\title{
Transcriptomic comparison of primary bovine horn core carcinoma culture and parental tissue at early stage
}

Sharadindu Shil ${ }^{1,2}$, R. S. Joshi ${ }^{2}$, C. G. Joshi ${ }^{3}$, A. K. Patel ${ }^{4}$, Ravi K. Shah ${ }^{3}$, Namrata Patel ${ }^{3}$, Subhash J. Jakhesara ${ }^{3}$, Sumana Kundu ${ }^{5}$, Bhaskar Reddy ${ }^{3}$, P. G. Koringa ${ }^{3}$ and D. N. Rank ${ }^{2}$

1. Veterinary Officer (WBAH \& VS), West Bengal Animal Resources Development Department, Bankura - 772152 , West Bengal, India; 2. Department of Animal Genetics \& Breeding, College of Veterinary Sciences and Animal Husbandry, Anand Agricultural University, Anand, Gujarat, India; 3. Department of Animal Biotechnology, College of Veterinary Sciences and Animal Husbandry, Anand Agricultural University, Anand, Gujarat, India; 4. Hester Biosciences Limited, Ahmedabad, Gujarat, India; 5. Veterinary Officer, MVC Sarenga, Government of West Bengal, Bankura, West Bengal, India.

Corresponding author: D. N. Rank, e-mail: dnrank@gmail.com, SS: dr.sharadindu@gmail.com, RS]: rsjoshi106@gmail.com, CG]: cgjoshi@aau.in, AKP: amrutkpatel@gmail.com, RKS: ravishah210@gmail.com, NP: namratapatel183@gmail.com, SJJ: drsubhash81@gmail.com, SK: skundukaiti@gmail.com, BR: 24breddy@gmail.com, PGK: prakashkoringa@gmail.com

Received: 19-09-2016, Accepted: 29-11-2016, Published online: 13-01-2017

doi: 10.14202/vetworld.2017.38-55 How to cite this article: Shil S, Joshi RS, Joshi CG, Patel AK, Shah RK, Patel N, Jakhesara SJ, Kundu S, Reddy B, Koringa PG, Rank DN (2017) Transcriptomic comparison of primary bovine horn core carcinoma culture and parental tissue at early stage, Veterinary World, 10(1): 38-55.

\begin{abstract}
Aim: Squamous cell carcinoma or SCC of horn in bovines (bovine horn core carcinoma) frequently observed in Bos indicus affecting almost $1 \%$ of cattle population. Freshly isolated primary epithelial cells may be closely related to the malignant epithelial cells of the tumor. Comparison of gene expression in between horn's SCC tissue and its early passage primary culture using next generation sequencing was the aim of this study.

Materials and Methods: Whole transcriptome sequencing of horn's SCC tissue and its early passage cells using Ion Torrent PGM were done. Comparative expression and analysis of different genes and pathways related to cancer and biological processes associated with malignancy, proliferating capacity, differentiation, apoptosis, senescence, adhesion, cohesion, migration, invasion, angiogenesis, and metabolic pathways were identified.

Results: Up-regulated genes in SCC of horn's early passage cells were involved in transporter activity, catalytic activity, nucleic acid binding transcription factor activity, biogenesis, cellular processes, biological regulation and localization and the down-regulated genes mainly were involved in focal adhesion, extracellular matrix receptor interaction and spliceosome activity.
\end{abstract}

Conclusion: The experiment revealed similar transcriptomic nature of horn's SCC tissue and its early passage cells.

Keywords: cummerbund, gene ontology, primary culture, RNA-sequencing, squamous cell carcinoma of horn, transcriptome profiling.

\section{Introduction}

Cancer cell lines, in general, are used as a model in testing of anticancer drugs presently used [1,2] as well as in the development of new therapies $[3,4]$. There is no bovine cell line of squamous cell carcinoma (SCC) origin. This is probably the first ever attempt to develop a SCC cell line of bovine origin. The horn cancer-based cell line can be used as an in vitro model in cancer research to define potential molecular markers as well as for the screening and characterization of cancer therapeutics similar to human lung and breast cancer cell lines $[5,6]$. The results of the research in cancer cell lines can usually

Copyright: Shil, et al. Open Access. This article is distributed under the terms of the Creative Commons Attribution 4.0 International License (http://creativecommons.org/licenses/by/4.0/), which permits unrestricted use, distribution, and reproduction in any medium, provided you give appropriate credit to the original author(s) and the source, provide a link to the Creative Commons license, and indicate if changes were made. The Creative Commons Public Domain Dedication waiver (http://creativecommons.org/ publicdomain/zero/1.0/) applies to the data made available in this article, unless otherwise stated. be extrapolated to in vivo tumors originated from squamous cells. Transcriptomic profiling of the initial passage cells and the SCC tissue was attempted in this study to confirm the initial passage cells represent the SCC tissue at molecular level.

Historically, in vitro cultures of SCC of horn (bovine horn core carcinoma [BHCC]) have been limited in availability and scope, compared to those from many other organs such as mammary tumors and endometrial cancer cell lines. Cell lines, those derived from metastases, do not span the range of most of cancer phenotypes, and in particular, are not representative of original SCC [7]. Furthermore, how extensively longterm culture alters the biological properties of cell lines are always of concern [8]. Adaptation of fresh cancerous tissue specimens which grow in vitro as primary cell cultures provides homogeneous cellular material, enriched in tumor cell component [7] and it also retains phenotypic, transcriptomics profile of the corresponding tissues from which they derive [8-10] at the first passages. 
Usually, up regulations of genes are involved in proliferation and metabolism. Cellular activity within a tissue is evinced by the transcriptome at a specific time. Pathophysiology of complex diseases, like cancer, can be evaluated by an unbiased method like genome-wide expression studies [10]. RNA sequencing (RNA-Seq) analysis is an affordable accurate and comprehensive tool to analyze transcriptome of complementary DNAs (cDNA) using next generation sequencing (NGS), followed by mapping of reads onto the reference genome making it possible to identify introns, exons, their flanking regions and thus providing an opportunity to understand the complexity of eukaryotic transcriptome [11].

SCC of horn of bovines is a SCC of horn core mucosa with least known genetic landscape, reported only in Bos indicus. This causes heavy economic losses due to subsequent metastasis and death of animal. In India, approximately $1 \%$ of the cattle population is affected by this tumor [12], most commonly in working bullocks, sometimes in cows and rarely in bulls, buffaloes, sheep, and goats [13-16]. The incidence of SCC of horns is more frequent in Kankrej breed than other zebu cattle, crossbred or non-descript cattle [17]. From Sumatra [18], Brazil [19], and Iraq [20] few cases were reported. Till date, the comparison of gene expression profile between cell culture and parental tissue of SCC of horn of bovines has not been performed. The study was designed to compare gene expression profiles in SCC affected horn tissue and primary cell culture derived from that tumor using Ion Torrent PGM sequencing platform.

\section{Materials and Methods}

\section{Ethical approval}

Aprroval for research work granted vide approval no. IAEC: 155/2011 of College of Veterinary Science and animal Husbandry, Anand Agricultural Universuty, Anand-388 001, Gujarat.

\section{Tissue collection}

Carcinomatous and normal horn core mucosa were collected during corrective surgery in RNAlater ${ }^{\circledR}$ (Thermo Fisher scientific, Massachusetts, USA) from clinically affected (left horn) and normal (right horn) horn of a Kankrej breed of bullock (age 7 years) from Rajkot, Gujarat, India. Necrotic tissues were not collected. Fresh tissues were cut into pea-sized segments and preserved in:

a. $10 \%$ neutral buffered formalin for histopathological studies

b. RNAlater ${ }^{\circledR}$ (Sigma-Aldrich, St. Louis, USA) for RNA extraction

c. Dulbecco's modification of Eagle's medium (DMEM) $(50 \mathrm{ml})$ (Thermo Fisher Scientific, Massachusetts, USA) with penicillin-streptomycin $(500 \mu l)$ (Thermo Fisher Scientific, Massachusetts, USA) + amphotericin-B $(500 \mu \mathrm{l})$ (Thermo Fisher Scientific, Massachusetts, USA) and brought to lab at $0-4^{\circ} \mathrm{C}$.

\section{Histopathology}

Horn SCC tissues were processed for histopathological studies and paraffin-embedded sections were cut at 5-6 $\mu$ thickness with section cutting machine (Leica, Germany) and stained with hematoxylin and eosin ( $\mathrm{H}$ and $\mathrm{E})$ [21]. The $\mathrm{H}$ and $\mathrm{E}$ stained sections were observed under light microscope and lesions were observed [21].

\section{Cell culture}

After removal of adipose tissue, tumor tissues (at $4^{\circ} \mathrm{C}$ ) were mechanically minced in $1 \mathrm{~mm}^{3}$ fragments. Then, the primary culture was established and incubated at $37^{\circ} \mathrm{C}$ and $5 \% \mathrm{CO}_{2}$ [21]. Similarly, tumor tissue explant culture was also performed by standard protocol [16]. DMEM and Ham's F12 50/50 mix (DMEM-F12) medium was changed twice weekly and split ratio for cells were 1:3 when cells reached up to $90 \%$ confluence. Cell morphology was observed in contrast phase, at $40 \times$ magnification, by inverted microscope. The cells were sampled at intervals, resuspended in a freezing medium (80\% DMEM, 10\% fetal bovine serum, and 10\% dimethyl sulfoxide), and stored at $-80^{\circ} \mathrm{C}$ at every two passages for cryopreservation.

Differential trypsinization was used for removal of the fibroblasts which detached sooner than the tumor cells. Isolation of pure population of tumor cells was done by plating approximately 10,000 detached cells in $100 \mathrm{~mm}$ Petri dishes and following dilution cloning [22]. These isolated clones were used for RNA-Seq purposes.

\section{Cell proliferation and doubling time assay}

Two counts were performed for each passage, in triplicate. For doubling time analysis, plating of cells in triplicate onto 6-well plates at a concentration of $2.5 \times$ $10^{4}$ cells/well in DMEM-F12 were done. After 24, 48 and $72 \mathrm{~h}$, cells were collected after trypsinization and counted in a Neubauer chamber. Doubling time (in hour) was calculated as described in a previous study [23].

\section{RNA isolation}

TRIzol (Sigma-Aldrich, St. Louis, USA) method as per manufacturer's instructions was used to isolate RNA from early passage cells of SCC of horns (pooled RNA of passage 2 and 3) and parental SCC tissue.

\section{Preparation of sample and transcriptome procedure}

All the protocols starting from mRNA isolation to library preparation were followed as per manufacturer's instructions. The detailed protocol steps can be accessed from Ion Torrent's "Ion Total RNA-Seq Kit" (Part No.: 4467098) using 316 chip.

\section{In silico gene expression analysis}

Sequence reads were generated from cDNA libraries of early passage cells and parental SCC horn tissue using Ion Torrent PGM chemistry using 316 chips [24]. Raw sequence reads (*.fastq files) were checked for quality control in FastQC v0.10.1. To avoid low quality data negatively influencing downstream analysis, the reads were trimmed and low quality sequences were filtered using PRINSEQ-lite 
version 0.20.2 with default parameters in Linux. This quality checked reads were aligned to the bosTau7.fa build of the cow genome (http://hgdownloadtest.cse. ucsc.edu/goldenPath/bosTau7/chromosomes/) using GMAP [25] and Samtools allowing for unique nongapped alignments to the genome. The default parameters for the GMAP method were used.

The resultant *.sam files were converted to *.bam files with Samtools then *. sorted.bam files were used in Cufflinks v 2.2.1. The resulting Cufflinks assemblies of all samples were combined together using Cuffcompare $\mathrm{v}$ 2.2.1. The differential expression was calculated by Cuffdiff based on transcript abundances [26]. Cuffdiff $v$ 2.2.1 was then employed on the combined transcripts to identify differentially expressed genes/transcripts.

\section{RNA-Seq data normalization}

The raw RNA-Seq read counts for cufflinks transcripts were first $\log _{2}$ transformed at fragments per kilobase of exon per million reads mapped (FPKM) and then quantile normalized.

\section{Functional annotation}

The genes differentially expressed in SCC horn tissue and the short-term primary culture was selected for functional categorization. The comparisons between expressed genes which produced Cuffdiff output with "Q value" $<0.01$ and "OK" marked test status were considered to be differentially expressed. Gene ontology (GO) and pathway analyses of up and down-regulated genes by DAVID database [27] and PANTHER database [28] were done, respectively. Gene set analyses were done in terms of biological processes, molecular function, and cellular component. The list of differentially expressed genes having $>5$ FPKM value and $\log _{2}$ fold change value above 2 (based on FPKM ratio), $\mathrm{p}=0.05$ and false discovery rate (FDR) value $5 \%$ were chosen.

Whole transcriptome analysis using NGS will identify several thousands of genes which are deregulated in number of cancer-related pathways. Since the depth of sequencing for each gene varies because of inherent methodology involved in NGS, it is globally accepted protocol to validate data obtained by this methodology via randomly selecting few of the genes through quantitative real-time polymerase chain reaction (PCR) $[29,30]$. Since it is practically impossible to validate all of the genes found in NGS-based study as well as it is economically non-feasible approach to study all identified genes, we have followed standard procedure to validate NGS data by selecting randomly selected sufficiently large set of transcripts and proved concordance of expression pattern using quantitative real-time PCR (Data not shown).

\section{Results}

\section{Histopathology of SCC tissue}

The tumor cells were tightly cohesive, featured with moderately high to abundant eosinophilic cytoplasm. The nucleus to cytoplasmic ratio was potentially increased with nuclei showing frequent prominent nucleoli. Mitotic activity was abundant including atypical forms such as ring and tripolar configurations. Intercellular bridges were focally present. Keratinization of individual epithelial cells (Figure-1a) and pleomorphic epithelial cells with enlarged nuclei (Figure-1b) were seen. Histopathology confirmed SCC of the horn core epithelium.

\section{Isolation of SCC horn epithelial cells}

Primary monolayer culture with finite mitotic lifespan (SCC early passage cells) was established from the bullock affected with SCC of horn (Figure-2) following the enzymatic disaggregation methods as described earlier [22]. By the first week, tumor cells were seen rounding up and growing throughout the T-25/T-75 flask (Figure-3) among the normal stromal fibroblasts that grew in parallel.

\section{Growth curve and population doubling time analysis}

Population doubling time ascertained around $28.1 \mathrm{~h}$ (Figure-4), and cell viability ranged from $85 \%$ to $94 \%$. The culture success rate was $90 \%$.

\section{Transcriptomic comparison between SCC horn tissue and its early passage cells}

The total number of genes differentially overexpressed in SCC horn tissue were 717 (8.40\% of total genes expressed) compared to early passage cells; 150 genes $(1.76 \%$ of total genes expressed) were differentially up-regulated which had more than 2-fold $\log _{2}$ value with maximum value of 6.03 -fold change. There were 746 genes $(8.74 \%$ of total genes expressed) which had differential over-expression in early passage cells than SCC horn tissue, 248 genes $(2.90 \%$ of total genes expressed) had more than 2-fold $\log _{2}$ value with maximum $\log _{2}$ value 7.02 . In this comparison, 5219 genes ( $\sim 38 \%$ of total genes no., i.e., 14513 no.) showed no expression at the terms of FPKM in both the samples 1600 genes had more than 5 FPKM value in early passage cells.

\section{Genes overexpressed in SCC early passage cells and SCC horn tissue}

Density plot and dispersion plot were derived for this comparison, respectively. Density plot assessed the distributions of FPKM scores across samples. Among the differentially expressed genes maximum genes had FPKM value between $\log _{10} 1$ and $\log _{10} 2$. Distribution of genes in SCC horn tissue ranged from $\log _{10} 0.2$ to $\log _{10} 3.7$ and for early passage SCC cells, it was $\log _{10} 0.7$ to $\log _{10} 3.7$. Dispersion plot showed normal dispersion of genes across samples. N-Myc downstream regulated 1, integrin alpha 6 , TP53 apoptosis effector (PERP), eukaryotic translation initiation factor 4 A1 (A1EIF4A1), desmoplakin, etc., genes were up-regulated (up-to 2-fold FPKM value) in SCC horn tissue compared to SCC early passage cells. Up-regulated genes (up to 2-fold FPKM value) in horn SCC early passage cells compared to parental tissue were coiled-coil domain containing 69 (CCDC69), CCDC94, Sec61 gamma subunit (SEC61G), Paladin, 


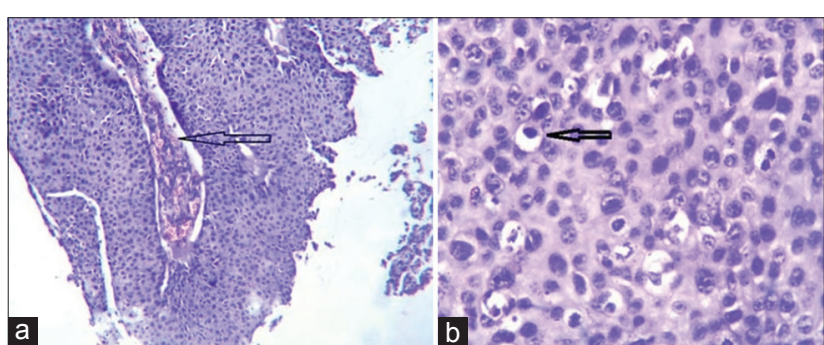

Figure-1: (a) Keratinization of individual horn squamous cell carcinoma (SCC) epithelial cells of parental tissue as seen in $\mathrm{H}$ and $\mathrm{E}$ stain at $100 \times$, (b) pleomorphic horn SCC cells with nucleolar polymorphism of parental tissue as seen in $\mathrm{H}$ and $\mathrm{E}$ stain at $100 \times$.

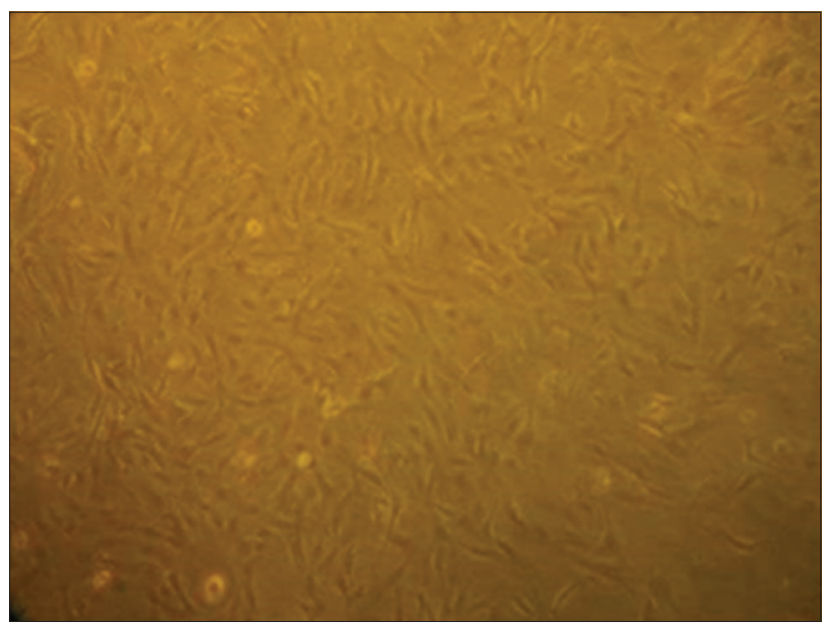

Figure-2: Primary monolayer culture of horn squamous cell carcinoma cells at $40 \times$.

Hedgehog $(\mathrm{Hh})$ receptor patched homolog 1 (PTCH1), Armadillo repeat containing X-linked 2 and thioredoxin, etc.

GO category of the genes differentially expressed above $2 \log _{2}$ fold change in SCC early passage cells compared to SCC horn tissue to be of calcium channel activity, calcium ion binding, protein phosphatase Type 2A activity and extracellular matrix (ECM) binding as per DAVID database (Table-1). The genes which were up-regulated in SCC horn tissue compared to its early passage cells showed major histocompatibility complex (MHC) Class I protein binding, MHC protein binding, procollagen proline 4-dioxygenase activity, peptidyl-proline dioxygenase activity, procollagen-proline dioxygenase activity, and protein disulfide isomerase activity.

The percentage of genes which showed up-regulation in SCC horn tissue than SCC early passage cells was $1.76 \%$. Genes up-regulated ( $\geq 2$-fold) in SCC horn tissue as compared to horn SCC early passage cells were involved in biogenesis, apoptotic response and response to stimulus in biological processes; structural molecular activity and translation regulator activity in molecular function; cell part, organelle and macromolecular complex in cellular component and the up-regulated genes ( $\geq 2$-fold) in horn SCC early passage cells were involved in cellular process, metabolic process, biological regulation in biological processes; catalytic

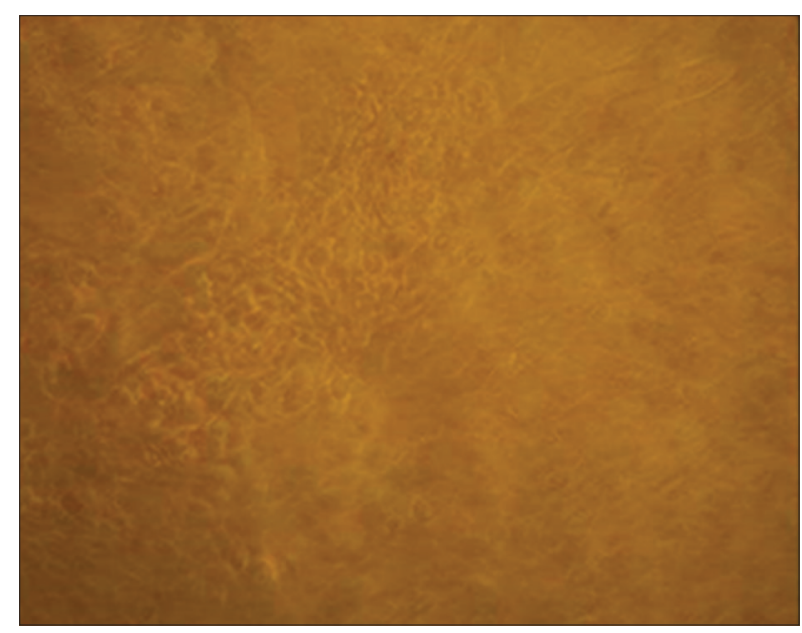

Figure-3: Rounded up horn squamous cell carcinoma malignant early passage cells on day 7 at $40 \times$.

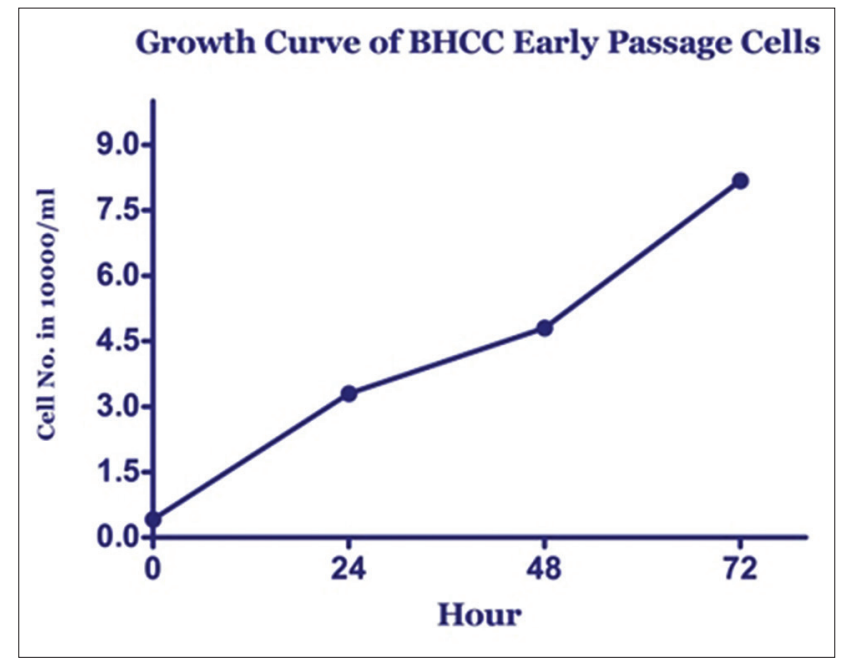

Figure-4: Growth curves of horn squamous cell carcinoma (bovine horn core carcinoma) early passage cells.

activity, enzyme regulator activity, binding in molecular function; membrane, extracellular region in cellular component as per PANTHER database.

There was no pathway in 5 FDR limit, but the lowest FDR value was found at transforming growth factor (TGF) beta signaling pathway and ribosomal pathway for differentially up-regulated genes in SCC early passage cells compared to SCC horn tissue in Kyoto Encyclopedia of Genes and Genomes (KEGG) pathways (Table-2). Surprisingly, most of the genes which showed top fold change (within first 20) were not detected by DAVID during pathway analysis. Focal adhesion, ECM-receptor interaction, thyroid cancer, and pathways in cancer were shown by the genes which were up-regulated in SCC horn tissue than SCC early passage cells (Table-3).

Genes up-regulated in SCC early passage cells compared to SCC horn tissue were involved in fibroblast growth factor signaling pathway, wnt signaling pathway, vascular endothelial growth factor signaling pathway, apoptosis signaling pathway and p53 signaling, epidermal growth factor receptor, cell cycle, 
Table-1: KEGG pathway of genes up in SCC early passage cells significantly over SCC horn tissue.

\begin{tabular}{|c|c|c|c|c|c|}
\hline KEGG pathway & p value & Genes & Fold change & Fold enrichment & FDR \\
\hline \multirow[t]{5}{*}{ bta04350:TGF-beta signaling pathway } & 0.031289 & MAPK1 & +2.01994 & 4.113924 & 29.86879 \\
\hline & & ROCK2 & +2.16513 & & \\
\hline & & TGFBR1 & +2.03972 & & \\
\hline & & PPP2CB & +2.30283 & & \\
\hline & & THBS1 & +3.95799 & & \\
\hline \multirow[t]{5}{*}{ bta03010:Ribosome } & 0.037987 & RPL32 & +2.62569 & 3.869048 & 35.09439 \\
\hline & & RPL23 & +3.21069 & & \\
\hline & & RPS17 & +3.94767 & & \\
\hline & & RPL3 & +3.20979 & & \\
\hline & & RPL24 & +2.62553 & & \\
\hline \multirow[t]{4}{*}{ bta05416:Viral myocarditis } & 0.06468 & SGCG & +3.62476 & 4.262295 & 52.58867 \\
\hline & & CASP9 & +2.03964 & & \\
\hline & & MYH11 & +3.03959 & & \\
\hline & & ITGB2 & +3.03967 & & \\
\hline \multirow[t]{4}{*}{ bta05212:Pancreatic cancer } & 0.080806 & VEGFC & +2.20969 & 3.880597 & 60.95311 \\
\hline & & MAPK1 & +2.01994 & & \\
\hline & & CASP9 & +2.03964 & & \\
\hline & & TGFBR1 & +2.03972 & & \\
\hline \multirow[t]{5}{*}{ bta04114:Oocyte meiosis } & 0.082876 & CCNE2 & +2.81728 & 2.981651 & 61.92363 \\
\hline & & MAPK1 & +2.01994 & & \\
\hline & & PPP2CB & +2.30283 & & \\
\hline & & PPP2R5E & +2.13926 & & \\
\hline & & ITPR2 & +2.03959 & & \\
\hline \multirow[t]{9}{*}{ bta05200:Pathways in cancer } & 0.086841 & CCNE2 & +2.81728 & 1.930693 & 63.72096 \\
\hline & & VEGFC & +2.20 & & \\
\hline & & MAPK1 & +2.01994 & & \\
\hline & & PIAS4 & +5.08415 & & \\
\hline & & CASP9 & +2.03964 & & \\
\hline & & TGFBR1 & +2.03972 & & \\
\hline & & MET & +2.03961 & & \\
\hline & & FGF10 & +3.62461 & & \\
\hline & & PTCH1 & +6.20952 & & \\
\hline \multirow[t]{6}{*}{ bta05010:Alzheimer's disease } & 0.089018 & MAPK1 & +2.01994 & 2.484076 & 64.67474 \\
\hline & & NDUFS5 & +5.6258 & & \\
\hline & & NDUFB6 & +3.62546 & & \\
\hline & & CASP9 & +2.03964 & & \\
\hline & & COX5A & +2.04022 & & \\
\hline & & ITPR2 & +2.03959 & & \\
\hline \multirow[t]{5}{*}{ bta04360:Axon guidance } & 0.094055 & MAPK1 & +2.01994 & 2.850877 & 66.79443 \\
\hline & & ROCK2 & +2.16513 & & \\
\hline & & MET & +2.03961 & & \\
\hline & & NTN4 & +5.94653 & & \\
\hline & & SEMA3C & +2.62465 & & \\
\hline
\end{tabular}

KEGG=Kyoto Encyclopedia of Genes and Genomes, SCC=Squamous cell carcinoma, TGF=Transforming growth factor, $\mathrm{FDR}=$ False discovery rate, $\mathrm{CASP9}=$ Caspase 9, PPP2R5E=Protein phosphatase 2 regulatory subunit $\mathrm{B}$ epsilon

inflammatory pathways mediated by chemokine and cytokine, etc., as per PANTHER database.

KEGG pathway of all genes, expressed in SCC early passage cells showed to be involved in focal adhesion, transforming growth factor TGF-beta signaling pathway, ubiquitin mediated proteolysis, pathways in cancer, prostate cancer mechanism within 5 FDR value (Table-4). KEGG pathways such as thyroid cancer, focal adhesion, small cell lung cancer, pathways in cancer, prostate cancer and spliceosome were shown to be involved when all the common genes ( $\geq 5$ FPKM) between SCC horn tissue and SCC early passage cells compared in DAVID (Table-5). To unveil the genes involved in horn cancer pathogenesis, both in-vivo and in-vitro genes were mined from common pathways up to 5 FDR (Table-6).
Genes that were uniquely expressed in SCC early passage cells as compared to SCC horn tissue showed involvement in metabolic and cellular process in biological processes; binding, catalytic activity in molecular function; heterotrimeric $\mathrm{G}$ protein signaling $\mathrm{G}_{\mathrm{i}}$ alpha pathway, Huntington disease, endothelin signaling pathway, angiogenesis, interleukin signaling pathway, etc., in pathway as per PANTHER database.

High proliferative and antiapoptotic potential are related to the up-regulation of growth hormone receptor and calmodulins [31]. The top 20 genes which were found to be up-regulated in SCC early passage cells in comparison to SCC horn tissue were investigated to have roles in other cancers as well as SCC in human and domestic animals (Table-7) [32-61] and vice versa (Table-8) [62-95]. 
Table-2: KEGG pathway analysis of significantly up regulated genes in SCC horn tissue in comparison to SCC early passage cells.

\begin{tabular}{|c|c|c|c|c|c|}
\hline KEGG pathway & p value & Genes & Fold change & Fold enrichment & FDR \\
\hline \multirow[t]{9}{*}{ bta04510:Focal adhesion } & 0.003554 & CDC42 & -3.18266 & 3.489795918 & 3.85308 \\
\hline & & ITGA6 & -5.25806 & & \\
\hline & & ILK & -2.2332 & & \\
\hline & & COL6A2 & -3.64219 & & \\
\hline & & PDGFRA & -2.10337 & & \\
\hline & & COL1A1 & -2.81067 & & \\
\hline & & PPP1CB & -4.46812 & & \\
\hline & & THBS2 & -2.81836 & & \\
\hline & & CTNNB1 & -2.95534 & & \\
\hline \multirow{5}{*}{ bta04512:ECM-receptor interaction } & 0.020151 & CD44 & -2.84292 & 4.704761905 & 20.12056515 \\
\hline & & ITGA6 & -5.25806 & & \\
\hline & & COL6A2 & -3.64219 & & \\
\hline & & COL1A1 & -2.81067 & & \\
\hline & & THBS2 & -2.81836 & & \\
\hline \multirow{3}{*}{ bta05216:Thyroid cancer } & 0.050381 & NCOA4 & -2.01925 & 8.142857143 & 43.47494112 \\
\hline & & MYC & -3.83476 & & \\
\hline & & CTNNB1 & -2.95534 & & \\
\hline \multirow[t]{9}{*}{ bta05200:Pathways in cancer } & 0.058738 & HSP90AB1 & -2.36404 & 2.096181047 & 48.72805735 \\
\hline & & CDC42 & -3.18266 & & \\
\hline & & HSP90AA1 & -2.39775 & & \\
\hline & & ITGA6 & -5.25806 & & \\
\hline & & NCOA4 & -2.01925 & & \\
\hline & & PDGFRA & -2.10337 & & \\
\hline & & MYC & -3.83476 & & \\
\hline & & STAT3 & -3.82663 & & \\
\hline & & CTNNB1 & 2.95534 & & \\
\hline \multirow[t]{4}{*}{ bta05412:ARVC } & 0.06167 & ITGA6 & -5.25806 & 4.342857143 & 50.4635378 \\
\hline & & DSP & -4.84482 & & \\
\hline & & GJA1 & -3.61259 & & \\
\hline & & CTNNB1 & -2.95534 & & \\
\hline \multirow{4}{*}{$\begin{array}{l}\text { bta04612:Antigen processing and } \\
\text { presentation }\end{array}$} & 0.066334 & HSP90AB1 & -2.36404 & 4.213219616 & 53.11403035 \\
\hline & & HSP90AA1 & -2.39775 & & \\
\hline & & PDIA3 & -2.03351 & & \\
\hline & & HSPA8 & -2.40875 & & \\
\hline \multirow[t]{5}{*}{ bta03040:Spliceosome } & 0.089962 & PRPF8 & -4.3062 & 2.892271663 & 64.66578307 \\
\hline & & SNRNP200 & -3.32965 & & \\
\hline & & DDX5 & -2.27017 & & \\
\hline & & HSPA8 & -2.40875 & & \\
\hline & & HNRNPU & -3.78478 & & \\
\hline
\end{tabular}

KEGG=Kyoto encyclopedia of genes and genomes, SCC=Squamous cell carcinoma, ARVC=Arrhythmogenic right ventricular cardiomyopathy, FDR=False discovery rate, ITGA6=Integrin alpha 6, ECM=Extracellular matrix

Table-3: GO of genes up regulated ( $\geq 2$-fold) in SCC early passage cells compared to SCC horn tissue via DAVID.

\begin{tabular}{lcccc}
\hline Term & Count & FDR & \% & p value \\
\hline GO:0046872 metal ion binding & 47 & 5.388398 & 21.17117 & 0.004134 \\
GO:0043169 cation binding & 47 & 6.774957 & 21.17117 & 0.005233 \\
GO:0043167 ion binding & 47 & 8.187385 & 21.17117 & 0.006369 \\
GO:0019992 diacylglycerol binding & 3 & 25.30314 & 1.351351 & 0.021584 \\
GO:0050840 ECM binding & 3 & 25.30314 & 1.351351 & 0.021584 \\
GO:0000287 magnesium ion binding & 7 & 34.49892 & 3.153153 & 0.031151 \\
GO:0019838 growth factor binding & 4 & 34.68459 & 1.801802 & 0.031356 \\
GO:0015405 P-P-bond-hydrolysis driven & 5 & 47.96599 & 2.252252 & 0.047687 \\
transmembrane transporter activity & & & & \\
GO:0015399 primary active & 5 & 47.96599 & 2.252252 & 0.047687 \\
transmembrane transporter activity & 7 & & & \\
GO:0008289 lipid binding & 3 & 60.62826 & 3.153153 & 0.067344 \\
GO:0005262 calcium channel activity & 4 & 74.51316 & 1.351351 & 0.097192 \\
GO:0005543 phospholipid binding & & 75.25716 & 1.801802 & 0.099191 \\
\hline
\end{tabular}

Count denotes gene count. GO=Gene ontology, SCC=Squamous cell carcinoma, FDR=False discovery rate, ECM=Extracellular matrix

\section{Discussion}

In this study, we compared gene expression profiles of the two conditions, i.e., in vivo cancer tissue and in vitro cancer cells at their early passages. The growth and survival rate of SCC early passage cells were good and it grew for the first few 
Table-4: KEGG pathway of all genes expressing $\geq 5$ FPKM in SCC early passage cells.

\begin{tabular}{|c|c|c|c|c|}
\hline Term & Count & FDR & $\%$ & p value \\
\hline bta04510:Focal adhesion & 48 & $4.06 \mathrm{E}-06$ & 3.292181 & $3.33 E-09$ \\
\hline bta04810: Regulation of actin cytoskeleton & 40 & 0.042391 & 2.743484 & $3.47 \mathrm{E}-05$ \\
\hline bta04350:TGF-beta signaling pathway & 22 & 0.0641 & 1.508916 & $5.25 E-05$ \\
\hline bta04512:ECM-receptor interaction & 21 & 0.091836 & 1.440329 & $7.52 \mathrm{E}-05$ \\
\hline bta04520: Adherens junction & 18 & 0.596801 & 1.234568 & $4.90 \mathrm{E}-04$ \\
\hline bta04120:Ubiquitin mediated proteolysis & 28 & 0.923001 & 1.920439 & 7.59E-04 \\
\hline bta05010:Alzheimer's disease & 30 & 2.493014 & 2.057613 & 0.002065 \\
\hline bta03010:Ribosome & 19 & 3.336116 & 1.303155 & 0.002775 \\
\hline bta05200:Pathways in cancer & 49 & 3.410855 & 3.360768 & 0.002838 \\
\hline bta05215:Prostate cancer & 18 & 7.802359 & 1.234568 & 0.00663 \\
\hline bta05016:Huntington's disease & 30 & 7.998577 & 2.057613 & 0.006803 \\
\hline bta04670:Leukocyte transendothelial migration & 22 & 8.071079 & 1.508916 & 0.006867 \\
\hline bta04114:Oocyte meiosis & 21 & 12.05085 & 1.440329 & 0.01046 \\
\hline bta00640:Propanoate metabolism & 9 & 15.5853 & 0.617284 & 0.013778 \\
\hline bta03050:Proteasome & 11 & 17.36369 & 0.754458 & 0.015496 \\
\hline bta04270:Vascular smooth muscle contraction & 20 & 17.64442 & 1.371742 & 0.015771 \\
\hline bta04530:Tight junction & 22 & 19.73693 & 1.508916 & 0.017843 \\
\hline bta03040:Spliceosome & 22 & 19.73693 & 1.508916 & 0.017843 \\
\hline bta05412:ARVC & 14 & 20.06711 & 0.960219 & 0.018174 \\
\hline bta05211:Renal cell carcinoma & 14 & 20.06711 & 0.960219 & 0.018174 \\
\hline bta04540:Gap junction & 16 & 20.36185 & 1.097394 & 0.018471 \\
\hline bta05212:Pancreatic cancer & 14 & 24.78525 & 0.960219 & 0.023053 \\
\hline bta05012:Parkinson's disease & 22 & 28.40347 & 1.508916 & 0.02699 \\
\hline bta05210:Colorectal cancer & 16 & 31.81445 & 1.097394 & 0.030871 \\
\hline bta05414:Dilated cardiomyopathy & 15 & 32.4247 & 1.028807 & 0.031584 \\
\hline bta04360:Axon guidance & 20 & 32.69897 & 1.371742 & 0.031907 \\
\hline bta04110:Cell cycle & 21 & 35.81972 & 1.440329 & 0.035663 \\
\hline bta05410:HCM & 14 & 38.80693 & 0.960219 & 0.03942 \\
\hline bta04150:mTOR signaling pathway & 11 & 39.72862 & 0.754458 & 0.040613 \\
\hline bta05222:Small cell lung cancer & 15 & 40.92982 & 1.028807 & 0.042193 \\
\hline bta04720:Long-term potentiation & 12 & 43.26753 & 0.823045 & 0.045355 \\
\hline bta04142: Lysosome & 19 & 48.66196 & 1.303155 & 0.053134 \\
\hline bta05213: Endometrial cancer & 10 & 55.76984 & 0.685871 & 0.064618 \\
\hline bta04666:Fc gamma R-mediated phagocytosis & 15 & 59.04418 & 1.028807 & 0.070491 \\
\hline bta00520:Amino sugar and nucleotide sugar metabolism & 9 & 60.46497 & 0.617284 & 0.073175 \\
\hline bta05220:Chronic myeloid leukemia & 13 & 69.07887 & 0.891632 & 0.091639 \\
\hline bta00190:Oxidative phosphorylation & 20 & 70.92517 & 1.371742 & 0.096207 \\
\hline
\end{tabular}

Count denotes gene count. ARVC=Arrhythmogenic right ventricular cardiomyopathy, KEGG=Kyoto encyclopedia of genes and genomes, SCC=Squamous cell carcinoma, HCM=Hypertrophic cardiomyopathy, FPKM=Fragments per kilobase of exon per million, $\mathrm{FDR}=$ False discovery rate, $\mathrm{ECM}=$ Extracellular matrix

passages without difficulties. The cellular compositions were homogeneous and were of morphological characteristics typical of squamous cell epithelium. These findings are more or less similar to previously described studies [31] that indicated that early passage cell cultures expressed genes similar to in vivo gene expression pattern. Hence, it could be used for in vitro investigation of transcriptomic alteration in cancers. Maximum value of differential gene expression in SCC early passage cells was 6.02-fold changes as compared to parental tissue. CCDC94 a dose-dependent modifier of the anti-apoptotic function of B-cell lymphoma 2 gene found to be up-regulated [96] in SCC early passage cells; PTCH1 overexpression might indicate invasive behavior of metastatic cells [97]; low Hh signaling [98] (Table-9). PTCH-1 overexpression in many epithelial-derived cancers correlates to overexpression of other " $\mathrm{Hh}$ pathway" members [99] and promotion of an alternate epidermal cell fate decision that potentiates SCC formation [100]. Netrin 4 overexpression might have control on reduced angiogenesis and metastasis [101]; high SATB homeobox 1 expression might have helped to promote cell cycle progression, proliferation, migration and increased invasive capability with strong expression of Vimentin (2750.61 FPKM) but low or lost E-cadherin (CDH1) expression - A pivotal event for epithelial to mesenchymal transition EMT [102]. EIF41A, X-linked gene overexpression along with EIF2A gene (fold change -0.56) downregulation shows improved cell proliferation as EIF2A gene is a negative regulator of protein translation, RPS7 gene overexpression (fold change -0.88 ) might have role in cancer cell cycle proliferation and cell cycle progression in BHCC early passage cells [103]. 14-3-3 gamma was not expressed in BHCC early passage cells denoting that 14-3-3 gamma might not be working at transcriptional level, but 14-3-3 theta which was found to be increased (fold change 0.30) might had a positive effect on tumor cell adhesion and growth [104]. In correlation to that Stratifin or 14-3-3 sigma was not expressed in BHCC early passage 
Table-5: KEGG pathway of all common genes ( $\geq 5$ FPKM) in between SCC horn tissue and SCC early passage cells.

\begin{tabular}{|c|c|c|c|c|}
\hline Term & Count & FDR & $\%$ & p value \\
\hline bta04510:Focal adhesion & 32 & $2.52 \mathrm{E}-06$ & 4.878049 & $2.12 \mathrm{E}-09$ \\
\hline bta04810: Regulation of actin cytoskeleton & 26 & 0.014261 & 3.963415 & $1.20 \mathrm{E}-05$ \\
\hline bta04512:ECM-receptor interaction & 15 & 0.027243 & 2.286585 & $2.30 \mathrm{E}-05$ \\
\hline bta05200:Pathways in cancer & 31 & 0.450733 & 4.72561 & $3.81 \mathrm{E}-04$ \\
\hline bta05215:Prostate cancer & 13 & 1.366688 & 1.981707 & 0.00115989 \\
\hline bta05412:ARVC & 11 & 1.968263 & 1.676829 & 0.00167511 \\
\hline bta04670:Leukocyte transendothelial migration & 15 & 2.062266 & 2.286585 & 0.001755881 \\
\hline bta04520:Adherens junction & 11 & 2.482973 & 1.676829 & 0.002118237 \\
\hline bta04120:Ubiquitin mediated proteolysis & 15 & 10.18146 & 2.286585 & 0.009015052 \\
\hline bta04530:Tight junction & 14 & 11.1892 & 2.134146 & 0.009957604 \\
\hline bta03040:Spliceosome & 14 & 11.1892 & 2.134146 & 0.009957604 \\
\hline bta04350:TGF-beta signaling pathway & 10 & 21.36772 & 1.52439 & 0.020069312 \\
\hline bta05213:Endometrial cancer & 7 & 35.30036 & 1.067073 & 0.036055226 \\
\hline bta05216:Thyroid cancer & 5 & 40.50522 & 0.762195 & 0.04284919 \\
\hline bta05414: Dilated cardiomyopathy & 9 & 41.73228 & 1.371951 & 0.044529994 \\
\hline bta00310:Lysine degradation & 6 & 44.89775 & 0.914634 & 0.049020477 \\
\hline bta05211: Renal cell carcinoma & 8 & 45.27855 & 1.219512 & 0.049576494 \\
\hline bta04540:Gap junction & 9 & 45.96247 & 1.371951 & 0.050584067 \\
\hline bta04110:Cell cycle & 12 & 47.42947 & 1.829268 & 0.052785299 \\
\hline bta05222:Small cell lung cancer & 9 & 48.09441 & 1.371951 & 0.053801616 \\
\hline bta05010:Alzheimer's disease & 14 & 53.2995 & 2.134146 & 0.062196631 \\
\hline bta05210:Colorectal cancer & 9 & 56.59508 & 1.371951 & 0.067966842 \\
\hline bta03010:Ribosome & 9 & 56.59508 & 1.371951 & 0.067966842 \\
\hline bta05410:HCM & 8 & 61.65301 & 1.219512 & 0.077654962 \\
\hline bta04720:Long-term potentiation & 7 & 64.27834 & 1.067073 & 0.083155068 \\
\hline bta04722: Neurotrophin signaling pathway & 11 & 64.64354 & 1.676829 & 0.0839493 \\
\hline
\end{tabular}

Count denotes gene count. HCM=Hypertrophic cardiomyopathy, FDR=False discovery rate, KEGG=Kyoto encyclopedia of genes and genomes, FPKM=Fragments per kilobase of exon per million, SCC=Squamous cell carcinoma, TGF=Transforming growth factor, ARVC=Arrhythmogenic right ventricular cardiomyopathy

Table-6: Genes common in pathways up to 5 FDR between SCC horn tissue and SCC early passage cells.

\begin{tabular}{|c|c|c|}
\hline KEGG pathway term & FDR & Genes \\
\hline bta04510:Focal adhesion & $2.5165 * \mathrm{E} 06$ & $\begin{array}{l}\text { TLN1, COL3A1, ITGB1, CTNNB1, MYL9, VCL, ACTG1, CDC42, ITGAV, } \\
\text { ILK, COL6A2, COL6A1, THBS2, PIK3R2, FN1, ACTB, COL4A1, ACTN4, } \\
\text { PPP1CB, FLNB, FLNA, LAMA4, PPP1CA, CCND1, ITGA6, ITGA5, JUN, } \\
\text { COL1A2, PDGFRA, RAP1A, PDGFRB, COL1A1, CRK }\end{array}$ \\
\hline $\begin{array}{l}\text { bta04810: Regulation of } \\
\text { actin cytoskeleton }\end{array}$ & 0.0142 & $\begin{array}{l}\text { RDX, PIP5K1A, ITGB1, MYL9, VCL, ACTG1, CDC42, EZR, GSN, ITGAV, } \\
\text { MSN, FGF2, FN1, APC, PIK3R2, ACTB, ACTN4, PPP1CB, ARPC1A, } \\
\text { PPP1CA, ITGA6, ITGA5, CFL1, PDGFRA, PDGFRB, CRK, PIP4K2C }\end{array}$ \\
\hline $\begin{array}{l}\text { bta04512:ECM-receptor } \\
\text { interaction }\end{array}$ & 0.0272 & $\begin{array}{l}\text { COL4A1, COL3A1, ITGB1, SDC1, LAMA4, ITGA6, CD44, ITGA5, ITGAV, } \\
\text { COL6A2, COL1A2, COL6A1, COL1A1, THBS2, FN1 }\end{array}$ \\
\hline $\begin{array}{l}\text { bta05200: Pathways in } \\
\text { cancer }\end{array}$ & 0.4507 & $\begin{array}{l}\text { HSP90AB1, TFG, MMP2, ITGB1, CTNNB1, CDC42, ITGAV, MYC, FGF2, } \\
\text { FN1, APC, PIK3R2, COL4A1, HSP90AA1, EPAS1, CREBBP, SMAD4, } \\
\text { CTNNA1, STAT3, LAMA4, HSP90B1, CCND1, CDKN1A, HIF1A, ITGA6, } \\
\text { NCOA4, JUN, PDGFRA, PDGFRB, JAK1, CRK }\end{array}$ \\
\hline bta05215:Prostate cancer & 1.3666 & $\begin{array}{l}\text { HSP90AB1, HSP90AA1, CREBBP, CTNNB1, CCND1, HSP90B1, CDKN1A, } \\
\text { ATF4, PDGFRA, CREB3L2, CREB3L1, PDGFRB, PIK3R2 }\end{array}$ \\
\hline bta05412:ARVC & 1.9682 & $\begin{array}{l}\text { ACTB, ACTG1, ACTN4, ITGA6, ITGA5, ITGAV, LMNA, DSP, GJA1, } \\
\text { CTNNA1, ITGB1, CTNNB1 }\end{array}$ \\
\hline $\begin{array}{l}\text { bta04670: Leukocyte } \\
\text { transendothelial migration }\end{array}$ & 2.0622 & $\begin{array}{l}\text { ACTB, ACTN4, GNAI2, GNAI1, CTNNA1, MMP2, ITGB1, VCL, MYL9, } \\
\text { CTNNB1, ACTG1, CDC42, EZR, RAP1A, MSN, PIK3R2 }\end{array}$ \\
\hline $\begin{array}{l}\text { bta04520:Adherens } \\
\text { junction }\end{array}$ & 2.4829 & $\begin{array}{l}\text { ACTB, ACTG1, CDC42, PVRL1, ACTN4, PTPRF, CREBBP, SMAD4, } \\
\text { CTNNA1, SNAI2, VCL, CTNNB1 }\end{array}$ \\
\hline
\end{tabular}

ARVC=Arrhythmogenic right ventricular cardiomyopathy, FDR=False discovery rate, KEGG=Kyoto Encyclopedia of Genes and Genomes, SCC=Squamous cell carcinoma, ECM=Extracellular matrix

cells. Cyclin D1 (FPKM in BHCC early passage cells is $~ 86$ ) which usually acts as an active switch for regulation of continuous cell cycle progression, had almost same expression in two samples, revealing the possible cycle chain in between these key players. Phosphoserine phosphatase [105]; inorganic pyrophosphates have a role in energy transduction, DNA replication and other metabolic processes that usually deregulate in cancer cells. It has been postulated that protein phosphatases are involved in the suppression of cellular growth and cancer development by antagonizing protein kinases in human cancers. Protein phosphatase 2 subunit B isoform alpha (PPP2R2A) is one of the four major Ser/Thr phosphatases and is a potential tumor suppressor gene [106], PP2, regulatory subunit $\mathrm{B}$, epsilon isoform (PPP2R5E) 
Table-7: Functions of highly expressed genes in SCC early passage cells in comparison to SCC horn tissue.

\begin{tabular}{|c|c|c|c|c|c|c|}
\hline $\begin{array}{l}\text { Gene ID } \\
\text { (ENSBTAG) }\end{array}$ & Gene title & Name & FPKM EP & FPKM HCT & $\begin{array}{l}\log _{2} \text { fold } \\
\text { change }\end{array}$ & $\begin{array}{l}\text { Roles and implications in } \\
\text { cancer of human and other }\end{array}$ \\
\hline 00000002834 & CCDC69 & $\begin{array}{l}\text { Coiled-coil domain } \\
\text { containing } 69\end{array}$ & 318.123 & 2.3446 & +7.084 & $\begin{array}{l}\text { Expressed in various cancer } \\
\text { cell lines such as HeLa, U2OS } \\
\text { and MDA-MB-231, exogenous } \\
\text { expression of CCDC69 in HeLa } \\
\text { cells destabilized microtubules and } \\
\text { disrupted the formation of bipolar } \\
\text { mitotic spindles [32] }\end{array}$ \\
\hline 00000012830 & CCDC94 & $\begin{array}{l}\text { Coiled-coil domain } \\
\text { containing } 94\end{array}$ & 842.151 & 10.503 & +6.325 & $\begin{array}{l}\text { Avoids DNA damaging apoptosis in } \\
\text { zebra-fish [33] }\end{array}$ \\
\hline 00000014971 & SEC61G & $\begin{array}{l}\text { Sec61 gamma } \\
\text { subunit }\end{array}$ & 4614.43 & 62.285 & +6.211 & $\begin{array}{l}\text { Proto-oncogene required for tumor } \\
\text { cell survival in GBM, involved in } \\
\text { the cytoprotective ER stress- } \\
\text { adaptive response to the tumor } \\
\text { microenvironment [34] }\end{array}$ \\
\hline 00000008583 & KIAA1274 & Paladin & 207.836 & 2.808 & +6.209 & $\begin{array}{l}\text { Vascular-restricted expression in } \\
\text { human brain, astrocytoma, and } \\
\text { glioblastomas. Paladin expression } \\
\text { is reactivated during pathological } \\
\text { tumor angiogenesis in the } \\
\text { adult [35] }\end{array}$ \\
\hline 00000048213 & PTCH1 & $\begin{array}{l}\text { Hh receptor } \\
\text { patched homolog } \\
1, \text { Uncharacterized } \\
\text { protein }\end{array}$ & 92.8954 & 1.2552 & +6.209 & $\begin{array}{l}\text { Inversely correlated with the } \\
\text { metastatic potential of colon cancer } \\
\text { cell lines, high expression associated } \\
\text { with low Hh signaling [36] }\end{array}$ \\
\hline 00000003183 & NTN4 & Netrin 4 & 123.963 & 2.010 & +5.946 & $\begin{array}{l}\text { Anti angiogenic effect, over } \\
\text { expression could decrease tumor } \\
\text { growth [37] }\end{array}$ \\
\hline 00000010232 & NDUFS5 & $\begin{array}{l}\text { NADH dehydrogenase } \\
\text { (ubiquinone) Fe-S } \\
\text { protein } 5,15 \mathrm{kDa} \\
\text { (NADH-coenzyme Q } \\
\text { reductase) }\end{array}$ & 1206.46 & 24.433 & +5.625 & $\begin{array}{l}\text { Highly expressed in endometrial } \\
\text { cancer }[38,85]\end{array}$ \\
\hline 00000019417 & ARMCX2 & $\begin{array}{l}\text { Armadillo repeat } \\
\text { containing, X-linked } 2\end{array}$ & 145.59 & 2.950 & +5.624 & $\begin{array}{l}\text { Might have a role in tumor } \\
\text { suppression, role in development } \\
\text { and tissue integrity [39] }\end{array}$ \\
\hline 00000021158 & SATB1 & SATB homeobox 1 & 161.255 & 3.7353 & +5.431 & $\begin{array}{l}\text { High levels of SATB1 expression } \\
\text { facilitate CRC and are associated } \\
\text { with poor prognosis, promotes } \\
\text { breast cancer metastasis, EMT } \\
\text { marker in prostrate cancer [40] }\end{array}$ \\
\hline 00000003130 & CHRNA3 & $\begin{array}{l}\text { Cholinergic receptor, } \\
\text { nicotinic, alpha } 3 \\
\text { (neuronal) }\end{array}$ & 1615.84 & 43.60 & +5.211 & $\begin{array}{l}\text { Polymorphism associated with high } \\
\text { chance for NSCLC }[41,85]\end{array}$ \\
\hline 00000017633 & EIF1AX & $\begin{array}{l}\text { Eukaryotic translation } \\
\text { initiation factor } 1 \mathrm{~A}, \mathrm{X} \\
\text { linked }\end{array}$ & 509.347 & 13.759 & +5.210 & $\begin{array}{l}\text { Mutation is having protective } \\
\text { role in uveal melanoma, over } \\
\text { expressed in metastatic prostate } \\
\text { cancer }[42,43]\end{array}$ \\
\hline 00000002428 & PPA2 & $\begin{array}{l}\text { Pyrophosphatase } \\
\text { (inorganic) } 2\end{array}$ & 255.495 & 6.903 & +5.209 & $\begin{array}{l}\text { Significantly increased in LNMPCa } \\
\text { tissues, supplies increased energy } \\
\text { requirement in metastasis } \\
\text { cells }[44,45]\end{array}$ \\
\hline 00000000753 & PIAS4 & $\begin{array}{l}\text { Protein inhibitor of } \\
\text { activated STAT, } 4\end{array}$ & 582.593 & 17.174 & +5.084 & $\begin{array}{l}\text { Necessary for proficient DNA } \\
\text { repair of DSBs, promotes BRCA1 } \\
\text { SUMOylation and DNA } \\
\text { repair }[46,47]\end{array}$ \\
\hline 00000013081 & $\mathrm{PSPH}$ & $\begin{array}{l}\text { Phosphoserine } \\
\text { phosphatase }\end{array}$ & 516.471 & 17.942 & +4.847 & $\begin{array}{l}\text { Up-regulated in CRC, increased } \\
\text { expression in non-small-cell lung } \\
\text { cancer corresponds to clinical } \\
\text { response. Suppression inhibited } \\
\text { proliferation, tumor formation } \\
\text { of MDAMB- } 468 \text { and MCF10 cells } \\
\text { respectively }[48,49]\end{array}$ \\
\hline 00000002953 & TXN & Thioredoxin & 3783.39 & 136.25 & +4.795 & $\begin{array}{l}\text { Promote cell growth, induces } \\
\text { VEGF, PTEN, angiogenesis and } \\
\text { inhibit apoptosis in tumor } \\
\text { cells }[50,51]\end{array}$ \\
\hline
\end{tabular}


Table-7: Continued...

\begin{tabular}{|c|c|c|c|c|c|c|}
\hline $\begin{array}{l}\text { Gene ID } \\
\text { (ENSBTAG) }\end{array}$ & Gene title & Name & FPKM EP & FPKM НСТ & $\begin{array}{c}\log _{2} \text { fold } \\
\text { change }\end{array}$ & $\begin{array}{l}\text { Roles and implications in } \\
\text { cancer of human and other }\end{array}$ \\
\hline 00000015522 & MRPS31 & $\begin{array}{l}\text { Mitochondrial } \\
\text { ribosomal protein S31 }\end{array}$ & 310.988 & 12.604 & +4.624 & $\begin{array}{l}\text { Up-regulated in human breast } \\
\text { cancer, CRC and found in } 77 \% \text { of } \\
\text { all types of cancer }[52,53,85]\end{array}$ \\
\hline 00000045742 & C5H12orf75 & $\begin{array}{l}\text { Chromosome } 12 \text { open } \\
\text { reading frame } 75\end{array}$ & 148.477 & 6.018 & +4.624 & $\begin{array}{l}\text { Highly expressed in granulosa } \\
\text { cells and membrane associated } \\
\text { granulosa cells before ovulation in } \\
\text { cattle [54] }\end{array}$ \\
\hline 00000009405 & TRPC4 & $\begin{array}{l}\text { Transient receptor } \\
\text { potential cation } \\
\text { channel, subfamily C, } \\
\text { member } 4\end{array}$ & 51.582 & 2.091 & +4.624 & $\begin{array}{l}\text { Highly expressed in NSCLC, LNCaP } \\
\text { cells activating store operated } \\
\text { channel calcium influx } \\
\text { factor }[55,56]\end{array}$ \\
\hline 00000008636 & PDE4B & $\begin{array}{l}\text { Phosphodiesterase } \\
4 B \text {, cAMP-specific }\end{array}$ & 41.5034 & 1.6824 & +4.624 & $\begin{array}{l}\text { Highly expressed in diffuse large } \\
\mathrm{BCL} \text {, expression of it avoids CAMP } \\
\text { mediated apoptosis. Induces } \\
\text { angiogenesis and cell proliferation } \\
\text { in lung cancer cell line }[57,58]\end{array}$ \\
\hline 00000008294 & $\mathrm{KCNJ} 2$ & $\begin{array}{l}\text { Potassium } \\
\text { inwardly-rectifying } \\
\text { channel, subfamily J, } \\
\text { member } 2\end{array}$ & 35.2224 & 1.4278 & +4.624 & $\begin{array}{l}\text { Expressed in medulloblastoma } \\
\text { with poor clinical outcome, } \\
\text { avoids apoptosis and induces cell } \\
\text { proliferation in oral cancer also. } \\
\text { Increased expression in papillary } \\
\text { thyroid cancer [59-61] }\end{array}$ \\
\hline
\end{tabular}

$\mathrm{EP}=\mathrm{SCC}$ early passage cells, $\mathrm{HCT}=\mathrm{SCC}$ horn tissue, CAMP=Cyclic adenosine monophosphate, SCC $=$ Squamous cell carcinoma, CCDC69=Coiled-coil domain containing 69, ER=Endoplasmic reticulum, GBM=Glioblastoma multiforme, $\mathrm{Hh}=$ Hedgehog, $\mathrm{NADH}=$ Nicotinamide adenine dinucleotide, $\mathrm{CRC}=$ Colorectal cancer, $\mathrm{EMT}=$ Epithelial mesenchymal transition, NSCLC $=$ Non-Small Cell Lung Cancer, LNM=Lymph node metastasis, VEGF=Vascular endothelial growth factor, $\mathrm{BCL}=\mathrm{B}$-cell lymphoma, $\mathrm{FPKM}=$ Fragments per kilobase of exon per million

Table-8: Functions of highly expressed genes in SCC horn tissue in comparison to SCC early passage cells.

\begin{tabular}{|c|c|c|c|c|c|c|}
\hline $\begin{array}{l}\text { Gene ID } \\
\text { (ENSBTAG) }\end{array}$ & $\begin{array}{l}\text { Gene } \\
\text { title }\end{array}$ & Name & $\begin{array}{l}\text { FPKM } \\
\text { HCT }\end{array}$ & $\begin{array}{l}\text { FPKM } \\
\text { EP }\end{array}$ & $\begin{array}{l}\log _{2} \text { fold } \\
\text { change }\end{array}$ & $\begin{array}{l}\text { Roles and implications in cancer of } \\
\text { human and other }\end{array}$ \\
\hline 00000000711 & NDRG1 & $\begin{array}{l}\mathrm{N}-\text { Myc downstream } \\
\text { regulated } 1\end{array}$ & 2001.28 & 30.4749 & -6.03715 & $\begin{array}{l}\text { Regulated by androgens, acts as } \\
\text { metastasis suppressor and negatively } \\
\text { correlated with it, found to be down } \\
\text { regulated in various cancers, prostate } \\
\text { cancer }[62,63]\end{array}$ \\
\hline 00000017266 & ITGA6 & Integrin, alpha 6 & 835.447 & 21.8316 & -5.2580 & $\begin{array}{l}\text { Prostate tumors persistently express } \\
\text { ITGA6, linked to increased tumor cell } \\
\text { invasion, migration, and metastasis. } \\
\text { Increased adhesion in AML } \\
\text { cells }[64,65]\end{array}$ \\
\hline 00000020097 & PERP & $\begin{array}{l}\text { PERP, TP53 apoptosis } \\
\text { effector }\end{array}$ & 1624.07 & 47.026 & -5.11001 & $\begin{array}{l}\text { Tumor suppressor. Loss induces } \\
\text { tumorigenesis, cell survival, and } \\
\text { desmosome loss by enhancing } \\
\text { inflammatory set of genes in } \\
\text { SCCs }[66,67]\end{array}$ \\
\hline 00000000132 & EIF4A1 & $\begin{array}{l}\text { Eukaryotic translation } \\
\text { initiation factor } 4 \mathrm{~A} 1\end{array}$ & 1613.66 & 54.0897 & -4.8988 & $\begin{array}{l}\text { Associated with highly metastasizing } \\
\text { melanoma. Overexpression is an early } \\
\text { marker for metastasizing hepatocellular } \\
\text { carcinoma and NSCLC }[68,69]\end{array}$ \\
\hline 00000015106 & DSP & Desmoplakin & 1837.68 & 63.9491 & -4.8448 & $\begin{array}{l}\text { Loss of desmoplakin, a cell adhesion } \\
\text { molecule, has been implicated in breast } \\
\text { cancer metastasis [70] }\end{array}$ \\
\hline 00000047330 & FABP5 & $\begin{array}{l}\text { Fatty acid binding } \\
\text { protein } 5 \text { (psoriasis } \\
\text { associated) }\end{array}$ & 1255.27 & 51.7861 & -4.5992 & $\begin{array}{l}\text { Involved in cell survival and growth, } \\
\text { enhances cell proliferation and } \\
\text { anchorage-independent growth in } \\
\text { prostate and breast cancer } \\
\text { cells }[71,72]\end{array}$ \\
\hline 00000012447 & PPP1CB & $\begin{array}{l}\text { Protein phosphatase } 1, \\
\text { catalytic subunit, beta } \\
\text { isozyme }\end{array}$ & 764.459 & 34.5396 & -4.4681 & $\begin{array}{l}\text { Enhances proliferation and colony } \\
\text { formation in leukemia cell line, } \\
\text { expressed in } 55 \text { cancer cell lines }[73,74]\end{array}$ \\
\hline 00000010365 & SQRDL & $\begin{array}{l}\text { Sulphide quinone } \\
\text { reductase-like (yeast) }\end{array}$ & 1206.17 & 57.2255 & -4.3976 & $\begin{array}{l}\text { Under expressed in ductal breast } \\
\text { carcinoma, but down regulation reduce } \\
\text { cell growth and induce apoptosis in } \\
\text { breast cancer cell line }[75,76]\end{array}$ \\
\hline
\end{tabular}


Table-8: Continued...

\begin{tabular}{|c|c|c|c|c|c|c|}
\hline $\begin{array}{l}\text { Gene ID } \\
\text { (ENSBTAG) }\end{array}$ & $\begin{array}{l}\text { Gene } \\
\text { title }\end{array}$ & Name & $\begin{array}{l}\text { FPKM } \\
\text { HCT }\end{array}$ & $\begin{array}{l}\text { FPKM } \\
\text { EP }\end{array}$ & $\begin{array}{l}\log _{2} \text { fold } \\
\text { change }\end{array}$ & $\begin{array}{l}\text { Roles and implications in cancer of } \\
\text { human and other }\end{array}$ \\
\hline 00000011969 & HSPB1 & $\begin{array}{l}\text { Heat shock } 27 \mathrm{kDa} \\
\text { protein } 1\end{array}$ & 2770.43 & 137.28 & -4.3349 & $\begin{array}{l}\text { Involved in DNA repair, recombination, } \\
\text { anti-apoptotic activity in HeLa cells, in most } \\
\text { of human cancers, high levels indicate } \\
\text { presence of metastatic tissues. Low levels } \\
\text { are associated with resistance }[77,78]\end{array}$ \\
\hline 00000011488 & PRPF8 & $\begin{array}{l}\text { PRP8 pre-mRNA } \\
\text { processing factor } 8 \\
\text { homolog (S. cerevisiae) }\end{array}$ & 230.594 & 11.6561 & -4.3062 & $\begin{array}{l}\text { Associated with spliceosome pathway, } \\
\text { tumor suppressor in myeloid } \\
\text { malignancies }[79,80]\end{array}$ \\
\hline 00000012927 & ALDOA & $\begin{array}{l}\text { Aldolase A, fructose- } \\
\text { bisphosphate, mRNA }\end{array}$ & 1162.91 & 60.5281 & -4.2639 & $\begin{array}{l}\text { Promote lung cancer metastasis, } \\
\text { invasion capability }[81,82]\end{array}$ \\
\hline 00000015107 & SLC16A1 & $\begin{array}{l}\text { Solute carrier family } \\
16, \text { member } 1 \\
\text { (monocarboxylic acid } \\
\text { transporter } 1 \text { ) }\end{array}$ & 465.287 & 28.411 & -4.0336 & $\begin{array}{l}\text { Positively associated with cell } \\
\text { survival, negatively with mir-124 in } \\
\text { medulloblastoma [83] }\end{array}$ \\
\hline 00000021035 & CTSK & Cathepsin $\mathrm{K}$, mRNA & 917.7 & 56.0406 & -4.0334 & $\begin{array}{l}\text { Inconsistent expression in horn cancer } \\
\text { tissue in bovine, involved in Hh signaling } \\
\text { and pre-osteoclast to osteoclast } \\
\text { differentiation in breast cancer }[84,86]\end{array}$ \\
\hline 00000010793 & CCDC80 & CCDC80, mRNA & 393.218 & 24.1296 & -4.0264 & $\begin{array}{l}\text { Tumor suppressor, down regulated in } \\
\text { thyroid carcinomas [87] }\end{array}$ \\
\hline 00000013315 & ATP5B & $\begin{array}{l}\text { ATP synthase, } \\
\mathrm{H}+\text { transporting, } \\
\text { mitochondrial F1 } \\
\text { complex, beta } \\
\text { polypeptide, mRNA }\end{array}$ & 853.925 & 53.4692 & -3.9973 & $\begin{array}{l}\text { Overexpressed and associated with poor } \\
\text { survival in breast cancer. High ATP5B } \\
\text { mRNA expression in ovarian cancer was } \\
\text { associated with worse OS [88] }\end{array}$ \\
\hline 00000003418 & MSN & Moesin (MSN), mRNA & 339.836 & 22.2957 & -3.93 & $\begin{array}{l}\text { High levels associated with poor } \\
\text { breast cancer survival, by increased } \\
\text { metastasis, invasion and EMT } \\
\text { changes [89] }\end{array}$ \\
\hline 00000008409 & MYC & $\begin{array}{l}\text { V-myc } \\
\text { myelocytomatosis viral } \\
\text { oncogene homolog } \\
\text { (avian) }\end{array}$ & 596.739 & 41.8222 & -3.8347 & $\begin{array}{l}\text { Correlated with distant metastasis, } \\
\text { aggressive breast cancer. Induces } \\
\text { genome instability [90] }\end{array}$ \\
\hline 00000021523 & STAT3 & $\begin{array}{l}\text { Signal transducer } \\
\text { and activator of } \\
\text { transcription } 3 \text { (acute- } \\
\text { phase response factor), } \\
\text { mRNA }\end{array}$ & 566.044 & 39.895 & -3.8266 & $\begin{array}{l}\text { Associated with increased angiogenesis, } \\
\text { metastasis, immune signaling and } \\
\text { inflammation in basal like breast } \\
\text { cancers }[91,92]\end{array}$ \\
\hline 00000008611 & IGFBP4 & $\begin{array}{l}\text { Insulin-like growth } \\
\text { factor binding protein } 4\end{array}$ & 627.819 & 44.5065 & -3.8182 & $\begin{array}{l}\text { Antagonist of wnt beta catenin signaling } \\
\text { pathway, higher in metastatic RCC. } \\
\text { Increases invasion, cell proliferation in } \\
\text { glioma }[93,94]\end{array}$ \\
\hline 00000007606 & HNRNPU & $\begin{array}{l}\text { Heterogeneous nuclear } \\
\text { ribonucleoprotein U } \\
\text { (scaffold attachment } \\
\text { factor } \mathrm{A}), \text { mRNA }\end{array}$ & 386.733 & 28.0595 & -3.7847 & $\begin{array}{l}\text { Involved in spliceosome pathway in } \\
\text { causing prostate cancer [95] }\end{array}$ \\
\hline
\end{tabular}

$\mathrm{EP}=\mathrm{SCC}$ early passage cells, $\mathrm{HCT}=\mathrm{SCC}$ horn tissue, NSCLC=Non-small cell lung cancer, ITGA6=Integrin, alpha $6, \mathrm{AML}=\mathrm{Acute}$ myeloid leukemia, ATP=Adenosine triphosphate, EMT=Epithelial-mesenchymal transition, RCC=Renal cell carcinoma, SCC=Squamous cell carcinoma, FPKM=Fragments per kilobase of exon per million, S. cerevisiae=Saccharomyces cerevisiae

expression are usually downregulated in cancer tissue and represses cell viability and growth promoting apoptosis in cells as a target of MicroRNA-23a (miR-23a) [107]. MiR-23a overexpression decreases PPP2R5E expression but as the cells were good and healthy by their phenotypes so we cannot support this hypothesis for our cell line. Glutaminase which indicates faster growth rate and change in Warburg effect [108] was increased (0.33-fold change) (not shown in table) in cells though, MYC oncogenic transcription factor expression in BHCC early passage cells was lower than BHCC tissue, and there was no expression of MiR-23a/b which are usually suppressed by MYC [109]. Solute carrier family 7A5, phosphoglycerate dehydrogenase decreased in cells, ACACA expression remained almost same, but ACLY expression was 1.5-fold lower in cells (Table-10). SERBP1 expression was also lower in cells by 1.5 fold. Moderate secretory carrier membrane proteins 3 expressions suggested a universal role in membrane traffic at the plasma membrane $[110,111]$.

Cytoplasmic serine hydroxymethyltransferase 1 (SHMT1) and thymidylate synthase genes of the de novo thymidylate biosynthesis pathway were found to be increased in early passage cells than BHCC tissue, but SHMT2 was not expressed in cells [110,112,113]. Tumor protein 53-induced nuclear protein 1, apoptosis activating factor- 1 was found to be increased in 


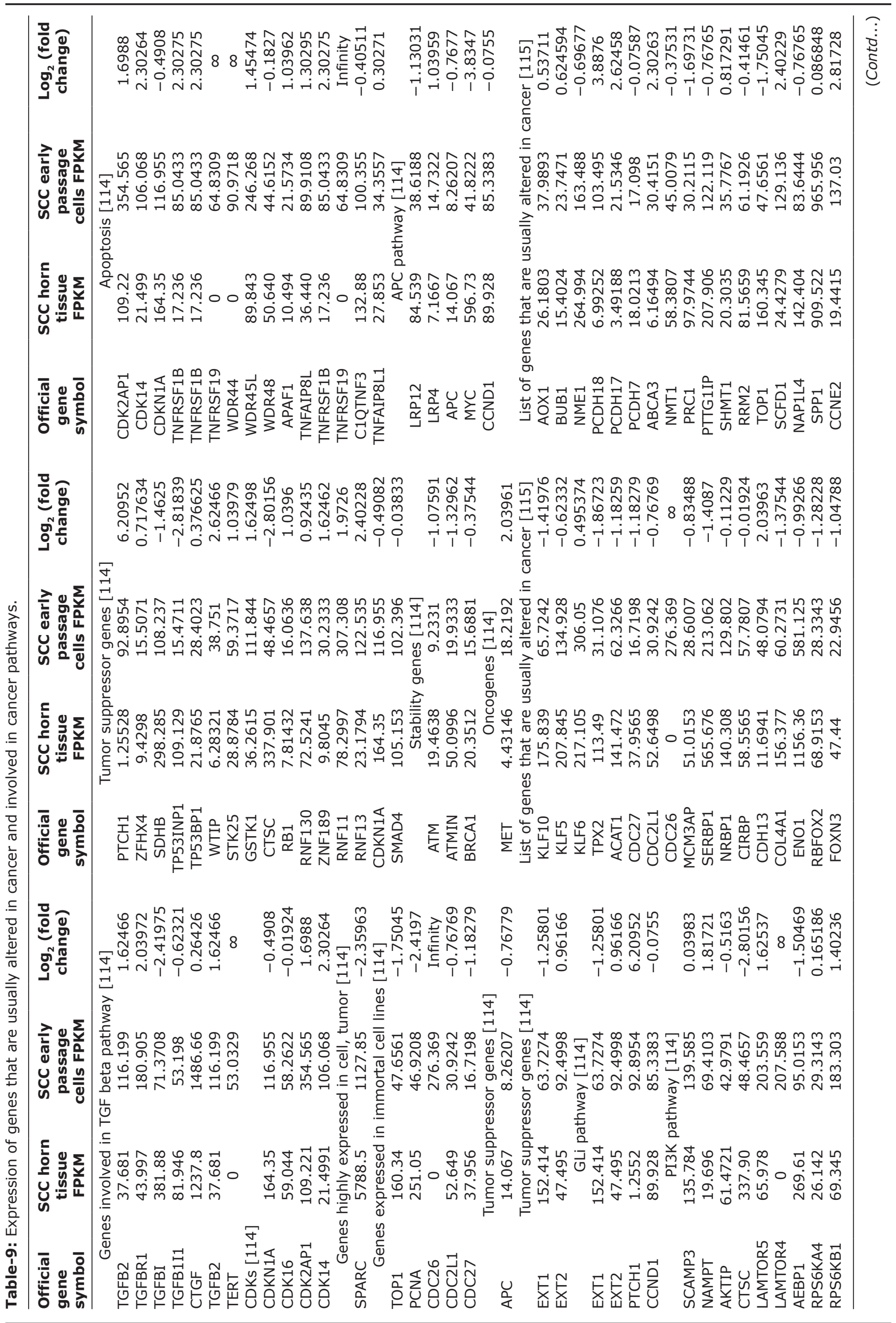

Veterinary World, EISSN: 2231-0916 


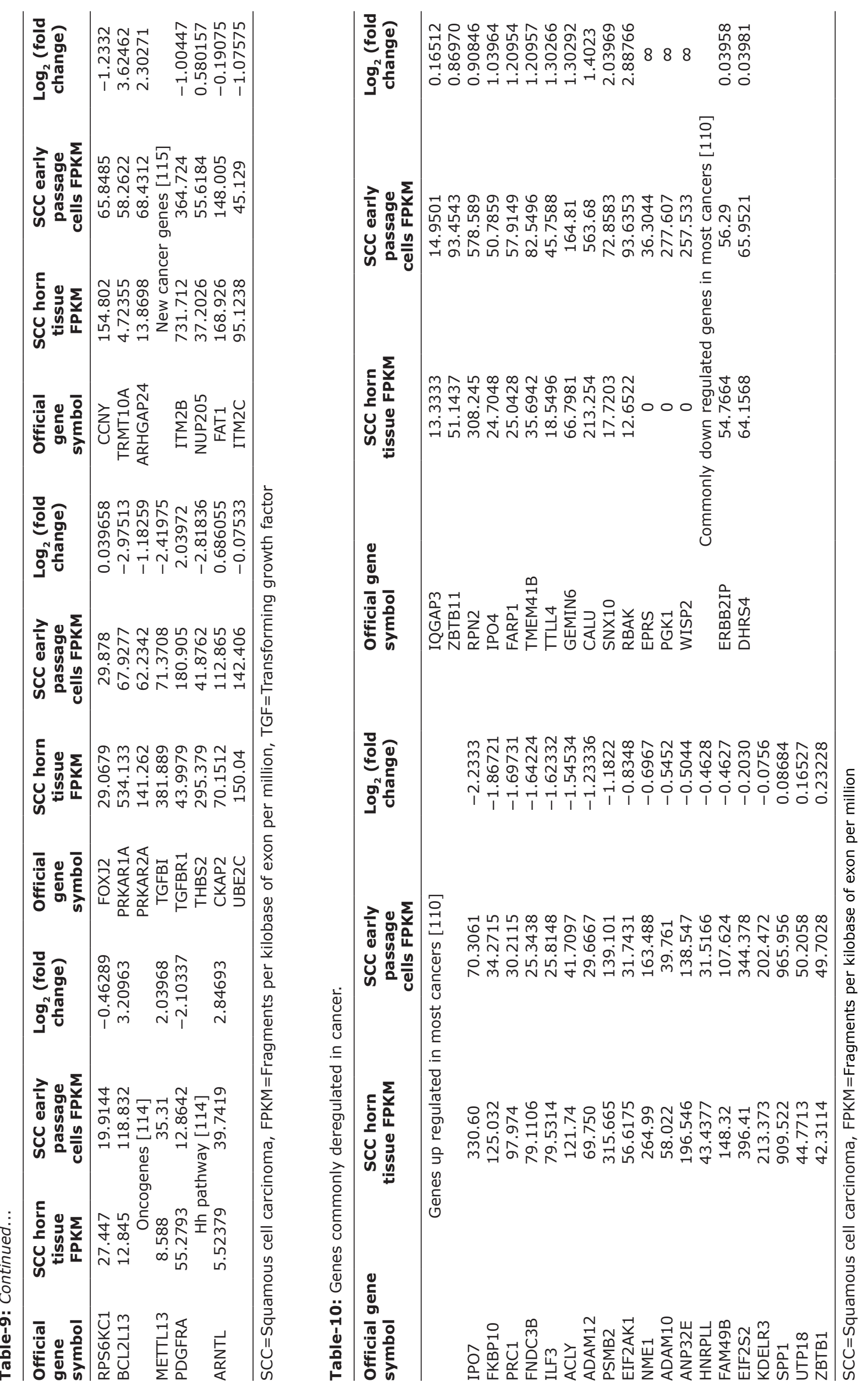


BHCC early passage cells ( $>1$-fold change) along with effector genes such as caspase 6 (CASP6) and caspase 9 (CASP9) (>2-fold change) but in contrast cytochrome $\mathrm{C}$ was not found to be expressed and the genes CASP3, CASP8 were not detected [114]. The above discussion denotes a number of key players in pathogenesis of SCC of horns in bovines which showed resemblance with human cancer studies in expression profiling.

\section{Conclusion}

The signaling pathway investigation in this first culture based approach revealed that many of the cancer-related pathways reported in the literatures for other carcinomas may also be held responsible for SCC of horn in bovines. Cells from bovine horn SCC surgical specimens may be adapted in vitro with high efficiency, independently from any clinicopathological characteristics.

Low-passage horn cancer cell lines would still closely reflect the phenotype of the horn cancer cells in vitro bypassing the obstacle for obtaining more detailed insights into the diversity of phenotypic and molecular changes occurring in horn cancer cells. Our result based on the pathway analysis suggested that primary culture of horn cancer in-vitro may serve as the model for SCC of horns in cattle.

This transcriptome-based approach demonstrates that epithelial cultures isolated from primary horn SCC retain complex characteristics of the malignant tissue. Thus, the opportunity for basic and clinical application of functional cells derived from SCC horn tissue, instead of a few immortal cell lines should not be missed.

\section{Authors' Contributions}

SS: Carried out laboratory experiment and written manuscript as part of MVSc. in Animal Genetics and Breeding. RSJ: Helped in manuscript correction. CGJ: Conceptualized the project. AKP: Helped in tissue culture work. RKS: Helped in tissue culture work. NP: Helped in bioinformatics work. SJJ: Helped in NGS work. SK: Helped in manuscript writing. BR: Helped in bioinformatics work. PGK: Helped in NGS work and sample collection. DNR: Helped in manuscript correction and improvement. All authors read and approved the final manuscript.

\section{Acknowledgments}

The authors sincerely acknowledge the help provided by Dr. M. G. Mardiya (Rajkot), Dr. Uday Koringa (Rajkot) during sample collection and Dr. J. V. Solanki (Anand) for valuable insights into the experiment. The authors thankfully acknowledge the funding provided by Anand Agricultural University under the project "Centre of Excellence in Animal Biotechnology" (B.H. 12928).

\section{Competing Interests}

The authors declare that they have no competing interests.

\section{References}

1. Yang, D.S. (2014) Novel prediction of anticancer drug chemosensitivity in cancer cell lines: Evidence of moderation by microRNA expressions. Conference Proceedings: Annual International Conference of the IEEE Engineering in Medicine and Biology Society IEEE Engineering in Medicine and Biology Society Annual Conference, 2014. p4780-4786.

2. Wei, W., Liu, Z., Chen, X. and Bi, F. (2014) Chemosensitivity of resistant colon cancer cell lines to lobaplatin, heptaplatin and dicycloplatin. Int. J. Clin. Pharmacol. Ther., 52(8): 702-707.

3. De la Cueva, A., Ramirez de Molina, A., Alvarez-Ayerza, N., Ramos, M.A., Cebrian, A., Del Pulgar, T.G. and Lacal, J.C. (2013) Combined 5-FU and ChoKalpha inhibitors as a new alternative therapy of colorectal cancer: Evidence in human tumor-derived cell lines and mouse xenografts. PLoS One, 8(6): e64961

4. Giuffrida, D. and Rogers, I.M. (2010) Targeting cancer stem cell lines as a new treatment of human cancer. Rec. Patents Anti Cancer Drug Discov., 5(3): 205-218.

5. Supino, R., Binaschi, M., Capranico, G., Gambetta, R.A., Prosperi, E., Sala, E. and Zunino, F. (1993) A study of cross-resistance pattern and expression of molecular markers of multidrug resistance in a human small-cell lung-cancer cell line selected with doxorubicin. Int. J. Cancer, 54(2): 309-314.

6. Lefevre, D., Riou, J.F., Ahomadegbe, J.C., Zhou, D.Y., Benard, J. and Riou, G. (1991) Study of molecular markers of resistance to m-AMSA in a human breast cancer cell line. Decrease of topoisomerase II and increase of both topoisomerase I and acidic glutathione $\mathrm{S}$ transferase. Biochem. Pharmacol., 41(12): 1967-1979.

7. Cifola, I., Bianchi, C., Mangano, E., Bombelli, S., Frascati, F., Fasoli, E., Ferrero, S., Di Stifano, V., Zipeto, M.A., Magni, F., Signorini, S., Battaglia, C. and Perego, R.A. (2011) Renal cell carcinoma primary cultures maintain genomic and phenotypic profile of parental tumor tissues. BMC Cancer, 11(1): 244.

8. Craven, R.A., Stanley, A.J., Hanrahan, S., Dods, J., Unwin, R., Totty, N., Harnden, P., Eardley, I., Selby, P.J. and Banks, R.E. (2006) Proteomic analysis of primary cell lines identifies protein changes present in renal cell carcinoma. Proteomics, 6(9): 2853-2864.

9. Perego, R.A., Bianchi, C., Corizzato, M., Eroini, B., Torsello, B., Valsecchi, C., Di Fonzo, A., Cordani, N., Favini, P., Ferrero, S., Pitto, M., Sarto, C., Magni, F., Rocco, F. and Mocarelli, P. (2005) Primary cell cultures arising from normal kidney and renal cell carcinoma retain the proteomic profile of corresponding tissues. J. Proteome Res., 4(5): 1503-1510.

10. Bianchi, C., Bombelli, S., Raimondo, F., Torsello, B., Angeloni, V., Ferrero, S., Di Stefano, V., Chinello, C., Cifola, I., Invernizzi, L., Brambilla, P., Magni, F., Pitto, M., Zanetti, G., Mocarelli, P. and Perego, R.A. (2010) Primary cell cultures from human renal cortex and renal-cell carcinoma evidence a differential expression of two spliced isoforms of Annexin A3. Am. J. Pathol., 176(4): 1660-1670.

11. Twine, N.A., Janitz, K., Wilkins, M.R. and Janitz, M. (2011) Whole transcriptome sequencing reveals gene expression and splicing differences in brain regions affected by Alzheimer's disease. PLoS One, 6(1): e16266.

12. Naik, S.N., Balakrishna, C.R. and Randelia, H.P. (1969) Epidemiology of horn cancer in Indian zebu cattle: Breed incidences. Br. Vet. J., 125: 222-230.

13. Joshi, B.P., Soni, P.B., Fefar, D.T., Ghodasara, D.J. and 
Prajapati, K.S. (2009) Epidemiological and pathological aspects of horn cancer in cattle of Gujarat. Indian J. Field Vet., 5: 15-18.

14. Burggraaf, H. (1935) Kanker aan de basis van de hoorns bijzebus. T. Diergeneesk, 62: 1121-1136.

15. Rezende, A.M.L. and Naves, P.T. (1975) Horn core cancer in a zebu cow, imported to Brazil. Pesqui. Agropecu. Bras. Ser. Vet., 10: 41-44.

16. Zubaidy, A.J. (1976) Horn cancer in cattle in Iraq. Vet. Pathol., 13: 435-454.

17. Kulkarni, H.V. (1953) Carcinoma of horn in bovines of Old Baroda state. Indian Vet. J., 29: 415-421.

18. Damodaran, S., Sundararaj, A. and Ramakrishnan, R. (1979) Horn cancer in bulls. Indian Vet. J., 56: 248-249.

19. Gupta, R.K., Sadana, J.R., Kuchroo, V.K. and Kalra, D.S. (1980) Horn cancer in an intact bull. Vet. Rec., 107: 312

20. Chattopadhyay, S.K., Jandrotia, V.S. and Ramkumar Iyer, P.K.R. (1982) Horn cancer in sheep. Indian Vet. J., 59: 319-320.

21. Luna, L.G., editor. (1968) Pathology AFIo. Manual of Histologic Staining Methods; of the Armed Forces Institute of Pathology. Blakiston Division, McGraw-Hill, New York.

22. Freshney, R.I. (2006) Basic principles of cell culture. Culture of Cells for Tissue Engineering. John Wiley \& Sons, Inc., Hobokan, New Jersey. p3-21.

23. Roth, V. (2006) Available from: http://www.doubling-time. com/compute.php. Accessed on 18-12-2016.

24. Koringa, P.G., Jakhesara, S.J., Bhatt, V.D., Meshram, C.P., Patel, A.K., Fefar, D.T. and Joshi, C.G. (2013) Comprehensive transcriptome profiling of squamous cell carcinoma of horn in Bos indicus. Vet. Comp. Oncol. DOI: 10.1111/vco.12079.

25. Wu, T.D. and Watanabe, C.K. (2005) GMAP: A genomic mapping and alignment program for mRNA and EST sequences. Bioinformatics, 21(9): 1859-1875.

26. Trapnell, C., Williams, B.A., Pertea, G., Mortazavi, A., Kwan, G., van Baren, M.J., Salzberg, S.L., Wold, B.J. and Pachter, L. (2010) Transcript assembly and quantification by RNA-Seq reveals unannotated transcripts and isoform switching during cell differentiation. Nat. Biotechnol., 28(5): 511-515.

27. Huang, D.W., Sherman, B.T. and Lempicki, R.A. (2008) Systematic and integrative analysis of large gene lists using DAVID bioinformatics resources. Nat. Prot., 4(1): 44-57.

28. Thomas, P.D., Kejariwal, A., Guo, N., Mi, H., Campbell, M.J., Muruganujan, A. and Ulitsky, B.L. (2006) Applications for protein sequence-function evolution data: $\mathrm{mRNA}$ /protein expression analysis and coding SNP scoring tools. Nuc. Acids Res., 34: W645-W650.

29. Gao, J., Wu, H., Wang, L., Zhang, H., Duan, H., Lu, J. and Liang, Z. (2016) Validation of targeted next-generation sequencing for RAS mutation detection in FFPE colorectal cancer tissues: Comparison with Sanger sequencing and ARMS-Scorpion real-time PCR. BMJ Open, 6(1): e009532.

30. Koringa, P.G., Jakhesara, S.J., Bhatt, V.D., Meshram, C.P., Patel, A.K., Fefar, D.T. and Joshi, C.G. (2016) Comprehensive transcriptome profiling of squamous cell carcinoma of horn in Bos indicus. Vet. Comp. Oncol., 14(2): $122-136$

31. Król, M., Polańska, J., Pawłowski, K.M., Turowski, P., Skierski, J., Majewska, A., Ugorski, M., Morty, R.E. and Motyl, T. (2010) Transcriptomic signature of cell lines isolated from canine mammary adenocarcinoma metastases to lungs. J. Appl. Genet., 51(1): 37-50.

32. Pal, D., Wu, D., Haruta, A., Matsumura, F. and Wei, Q. (2010) Role of a novel coiled-coil domain-containing protein CCDC69 in regulating central spindle assembly. Cell Cycle, 9(20): 4117-4129.

33. Sorrells, S., Carbonneau, S., Harrington, E., Chen, A.T., Hast, B., Milash, B., Pyati, U., Major, M.B., Zhou, Y., Zon, L.I., Stewart, R.A., Look, A.T. and Jette, C. (2012) Ccdc94 protects cells from ionizing radiation by inhibiting the expression of p53. PLoS Genet., 8(8): e1002922.

34. Lu, Z., Zhou, L., Killela, P., Rasheed, A.B., Di, C., Poe, W.E., McLendon, R.E., Bigner, D.D., Nicchitta, C. and Yan, H. (2009) Glioblastoma proto-oncogene SEC61 $\gamma$ is required for tumor cell survival and response to endoplasmic reticulum stress. Cancer Res., 69(23): 9105-9111.

35. Wallgard, E., Nitzsche, A., Larsson, J., Guo, X., Dieterich, L.C., Dimberg, A., Olofsson, T., Pontén, F.C., Mäkinen, T., Kalén, M. and Hellström, M. (2012) Paladin (X99384) is expressed in the vasculature and shifts from endothelial to vascular smooth muscle cells during mouse development. Dev. Dyn., 241(4): 770-786.

36. Wang, H., Ke, F. and Zheng, J. (2014) Hedgehog-gliomaassociated oncogene homolog-1 signaling in colon cancer cells and its role in the celecoxib-mediated anti-cancer effect. Oncol. Lett., 8(5): 2203-2208.

37. Zhao, M., Tang, Q., Wu, W., Xia, Y., Chen, D. and Wang, X. (2014) miR-20a contributes to endometriosis by regulating NTN4 expression. Mol. Biol. Rep., 41(9): 5793-5797.

38. Wang, L., McDonnell, S.K., Hebbring, S.J., Cunningham, J.M., St. Sauver, J., Cerhan, J.R., Isaya, G., Schaid, D.J. and Thibodeau, S.N. (2008) Polymorphisms in mitochondrial genes and prostate cancer risk. Cancer Epidemiol. Biomarkers Prev., 17(12): 3558-3566.

39. Zeller, C., Dai, W., Steele, N.L., Siddiq, A., Walley, A.J., Wilhelm-Benartzi, C.S.M., Rizzo, S., Van Der Zee, A., Plumb, J.A. and Brown, R. (2012) Candidate DNA methylation drivers of acquired cisplatin resistance in ovarian cancer identified by methylome and expression profiling. Oncogene, 31(42): 4567-4576.

40. Brocato, J. and Costa, M. (2015) SATB1 and 2 in colorectal cancer. Carcinogenesis, 36(2): 186-191.

41. Xiao, M., Chen, L., Wu, X. and Wen, F. (2014) The association between the rs6495309 polymorphism in CHRNA3 gene and lung cancer risk in Chinese: A meta-analysis. Sci. Rep., 4: 6372.

42. Ewens, K.G., Kanetsky, P.A., Richards-Yutz, J., Purrazzella, J., Shields, C.L., Ganguly, T. and Ganguly, A. (2014) Chromosome 3 status combined with BAP1 and EIF1AX mutation profiles are associated with metastasis in uveal melanoma gene mutations associated with metastasis in UM. Invest. Ophthalmol. Visual Sci., 55(8): 5160-5167.

43. Chandran, U.R., Ma, C., Dhir, R., Bisceglia, M., LyonsWeiler, M., Liang, W., Michalopoulos, G., Becich, M. and Monzon, F.A. (2007) Gene expression profiles of prostate cancer reveal involvement of multiple molecular pathways in the metastatic process. BMC Cancer, 7(1): 1.

44. Pang, J., Liu, W.P., Liu, X.P., Li, L.Y., Fang, Y.Q., Sun, Q.P., Liu, S.J., Li, M.T., Su, Z.L. and Gao, X. (2009) Profiling protein markers associated with lymph node metastasis in prostate cancer by DIGE based proteomics analysis. J. Proteome Res., 9(1): 216-226.

45. Schönthal, A.H. (2001) Role of serine/threonine protein phosphatase 2A in cancer. Cancer Lett., 170(1): 1-13.

46. Bartek, J. and Hodny, Z. (2010) SUMO boosts the DNA damage response barrier against cancer. Cancer Cell, 17(1): 9-11.

47. Wei, J., Costa, C., Ding, Y., Zou, Z., Yu, L., Sanchez, J.J., Qian, X., Chen, H., Gimenez-Capitan, A., Meng, F. and Moran, T. (2011) mRNA expression of BRCA1, PIAS1, and PIAS4 and survival after second-line docetaxel in advanced gastric cancer. J. Natl. Cancer Inst., 103(20): 1552-1556.

48. Jovov, B., Araujo-Perez, F., Sigel, C.S., Stratford, J.K., McCoy, A.N., Yeh, J.J. and Keku, T. (2012) Differential gene expression between African American and European American colorectal cancer patients. PLoS One, 7(1): e30168.

49. Possemato, R., Marks, K.M., Shaul, Y.D., Pacold, M.E., Kim, D., Birsoy, K., Sethumadhavan, S., Woo, H.K., Jang, H.G., Jha, A.K. and Chen, W.W. (2011) Functional genomics reveal that the serine synthesis pathway is essential in breast cancer. Nature, 476(7360): 346-350. 
50. Cadenas, C., Franckenstein, D., Schmidt, M., Gehrmann, M., Hermes, M., Geppert, B., Schormann, W., Maccoux, L.J., Schug, M., Schumann, A. and Wilhelm, C. (2010) Role of thioredoxin reductase 1 and thioredoxin interacting protein in prognosis of breast cancer. Breast Cancer Res., 12(3): 1.

51. Arner, E.S. and Holmgren, A. (2006) The thioredoxin system in cancer. Semin. Cancer Biol., 16(6): 420-426.

52. Sotgia, F., Menezes, D.W., Outschoorn, U.E.M., Salem, A.F., Tsirigos, A., Lamb, R., Sneddon, S., Hulit, J., Howell, A. and Lisanti, M.P. (2012) Mitochondria "fuel" breast cancer metabolism: Fifteen markers of mitochondrial biogenesis label epithelial cancer cells, but are excluded from adjacent stromal cells. Cell Cycle, 11(23): 4390-4401.

53. Budinska, E., Popovici, V., Tejpar, S., D'Ario, G., Lapique, N., Sikora, K.O., Di Narzo, A.F., Yan, P., Hodgson, J.G., Weinrich, S. and Bosman, F. (2013) Gene expression patterns unveil a new level of molecular heterogeneity in colorectal cancer. J. Pathol., 231(1): 63-76.

54. Christenson, L.K., Gunewardena, S., Hong, X. Spitschak, M., Baufeld, A. and Vanselow, J. (2013) Research resource: Preovulatory LH surge effects on follicular theca and granulosa transcriptomes. Mol. Endocrinol., 27(7): 1153-1171

55. Abeele, F.V., Lemonnier, L., Thébault, S., Lepage, G., Parys, J.B., Shuba, Y., Skryma, R. and Prevarskaya, N. (2004) Two types of store-operated $\mathrm{Ca} 2+$ channels with different activation modes and molecular origin in $\mathrm{LNCaP}$ human prostate cancer epithelial cells. J. Biol. Chem., 279(29): 30326-30337.

56. Zhang, Q., He, J., Lu, W., Yin, W., Yang, H., Xu, X. and Wang, D. (2010) Expression of transient receptor potential canonical channel proteins in human non-small cell lung cancer. Zhongguo Fei Ai Za Zhi, 13(6): 612-616.

57. Kashiwagi, E., Shiota, M., Yokomizo, A., Itsumi, M., Inokuchi, J., Uchiumi, T. and Naito, S. (2012) Downregulation of phosphodiesterase 4B (PDE4B) activates protein kinase $A$ and contributes to the progression of prostate cancer. Prostate, 72(7): 741-751.

58. Mareddy, J., Nallapati, S.B., Anireddy, J., Devi, Y.P., Mangamoori, L.N., Kapavarapu, R. and Pal, S. (2013) Synthesis and biological evaluation of nimesulide based new class of triazole derivatives as potential PDE4B inhibitors against cancer cells. Bioorgan. Med. Chem. Lett., 23(24): 6721-6727.

59. Valdora, F., Freier, F., Garzia, L., Ramaswamy, V., Seyler, C., Hielscher, T., Brady, N., Northcott, P.A., Kool, M., Jones, D.T. and Witt, H. (2013) KCNJ2 constitutes a marker and therapeutic target of high-risk medulloblastomas. Cancer Res., 738 Suppl: 5050.

60. Kim, H.S., Kim, D.H., Kim, J.Y., Jeoung, N.H., Lee, I.K., Bong, J.G. and Jung, E.D. (2010) Microarray analysis of papillary thyroid cancers in Korean. Korean J. Intern. Med., 25(4): 399-407.

61. Li, Y.L. (2013) Silencing of KCNJ2, a potassium influx channel, increases cisplatin-induced cell death in oral cancer. Cancer Res., 738 Suppl: 2119.

62. Kovacevic, Z. and Richardson, D.R. (2006) The metastasis suppressor, Ndrg-1: A new ally in the fight against cancer. Carcinogenesis, 27(12): 2355-2366.

63. Ghalayini, M.K., Dong, Q., Richardson, D.R. and Assinder, S.J. (2013) Proteolytic cleavage and truncation of NDRG1 in human prostate cancer cells, but not normal prostate epithelial cells. Biosci. Rep., 33(3): e00042.

64. Yamakawa, N., Kaneda, K., Saito, Y., Ichihara, E. and Morishita, K. (2012) The increased expression of integrin a6 (ITGA6) enhances drug resistance in EVI1 high leukemia. PLoS One, 7(1): e30706.

65. Cheng, I., Plummer, S.J., Neslund-Dudas, C., Klein, E.A., Casey, G., Rybicki, B.A. and Witte, J.S. (2010) Prostate cancer susceptibility variants confer increased risk of disease progression. Cancer Epidemiol. Biomarkers Prev., 19(9): 2124-2132
66. Dusek, R.L., Bascom, J.L., Vogel, H., Baron, S., Borowsky, A.D., Bissell, M.J. and Attardi, L.D. (2012) Deficiency of the p53/p63 target Perp alters mammary gland homeostasis and promotes cancer. Breast Cancer Res., 14(2): 1.

67. Beaudry, V.G., Jiang, D., Dusek, R.L., Park, E.J., Knezevich, S., Ridd, K., Vogel, H., Bastian, B.C. and Attardi, L.D. (2010) Loss of the p53/p63 regulated desmosomal protein Perp promotes tumorigenesis. PLoS Genet., 6(10): e1001168.

68. Ji, P., Diederichs, S., Wang, W., Böing, S., Metzger, R., Schneider, P.M., Tidow, N., Brandt, B., Buerger, H., Bulk, E. and Thomas, M. (2003) MALAT-1, a novel noncoding RNA, and thymosin $\beta 4$ predict metastasis and survival in early-stage non-small cell lung cancer. Oncogene, 22(39): 8031-8041.

69. Lomnytska, M.I., Becker, S., Gemoll, T., Lundgren, C., Habermann, J., Olsson, A., Bodin, I., Engström, U., Hellman, U., Hellman, K. and Hellström, A.C. (2012) Impact of genomic stability on protein expression in endometrioid endometrial cancer. Br. J. Cancer, 106(7): 1297-1305

70. Pang, H., Rowan, B.G., Al-Dhaheri, M. and Faber, L.E. (2004) Epidermal growth factor suppresses induction by progestin of the adhesion protein desmoplakin in T47D breast cancer cells. Breast Cancer Res., 6(3): 1.

71. Morgan, E., Kannan-Thulasiraman, P. and Noy, N. (2010) Involvement of fatty acid binding protein 5 and PPAR/in prostate cancer cell growth. PPAR Res., 2010: Article ID: 234629,9 .

72. Levi, L., Lobo, G., Doud, M.K., Von Lintig, J., Seachrist, D., Tochtrop, G.P. and Noy, N. (2013) Genetic ablation of the fatty acid-binding protein FABP5 suppresses HER2induced mammary tumorigenesis. Cancer Res., 73(15): 4770-4780

73. Takakura, S., Kohno, T., Manda, R., Okamoto, A., Tanaka, T. and Yokota, J. (2001) Genetic alterations and expression of the protein phosphatase 1 genes in human cancers. Int. $J$. Oncol., 18(4): 817-824.

74. Velusamy, T., Palanisamy, N., Kalyana-Sundaram, S., Sahasrabuddhe, A.A., Maher, C.A., Robinson, D.R., Bahler, D.W., Cornell, T.T., Wilson, T.E., Lim, M.S. and Chinnaiyan, A.M. (2013) Recurrent reciprocal RNA chimera involving YPEL5 and PPP1CB in chronic lymphocytic leukemia. Proc. Natl. Acad. Sci., 110(8): 3035-3040.

75. Abba, M.C., Drake, J.A., Hawkins, K.A., Hu, Y., Sun, H., Notcovich, C., Gaddis, S., Sahin, A., Baggerly, K. and Aldaz, C.M. (2004) Transcriptomic changes in human breast cancer progression as determined by serial analysis of gene expression. Breast Cancer Res., 6(5): 1.

76. Honma, K., Iwao-Koizumi, K., Takeshita, F., Yamamoto, Y., Yoshida, T., Nishio, K., Nagahara, S., Kato, K. and Ochiya, T. (2008) RPN2 gene confers docetaxel resistance in breast cancer. Nat. Med., 14(9): 939-948.

77. Arrigo, A.P., Simon, S., Gibert, B., Remy, C.K., Nivon, M., Czekalla, A., Guillet, D., Moulin, M., Diaz-Latoud, C. and Vicart, P. (2007) Hsp27 (HspB1) and $\alpha$ B-crystallin (HspB5) as therapeutic targets. FEBS Lett., 581(19): 3665-3674.

78. Heinrich, J.C., Tuukkanen, A., Schroeder, M., Fahrig, T. and Fahrig, R. (2011) RP101 (brivudine) binds to heat shock protein HSP27 (HSPB1) and enhances survival in animals and pancreatic cancer patients. J. Cancer Res. Clin. Oncol., 137(9): 1349-1361.

79. Fan, J., Zhang, Y.Q., Li, P., Tong, C., Tan, L. and Zhu, Y.S. (2004) Interaction between plasminogen activator inhibitor type-2 and pre-mRNA processing factor 8. Acta Biochim. Biophys. Sin., 36(9): 623-628.

80. Kozaric, A.K., Przychodzen, B., Singh, J., Konarska, M.M., Clemente, M.J., Otrock, Z.K., Nakashima, M., Hsi, E.D., Yoshida, K., Shiraishi, Y. and Chiba, K. (2015) PRPF8 defects cause missplicing in myeloid malignancies. Leukemia, 29(1): 126-136. 
81. Chang, Y.C., Jan, Y.H., Chan, Y.C., Yang, Y.F., Su, C.Y., Lai, T.C., Liu, Y.P. and Hsiao, M. (2013) Identification of ALDOA as a new Lung adeonocarcinoma predict gene involve cancer metabolism and tumor metastasis. FASEB J., 27(1_MeetingAbstracts): 58-61.

82. Migneco, G., Menezes, D.W., Chiavarina, B., Cros, R.C., Pavlides, S., Pestell, R.G., Fatatis, A., Flomenberg, N., Tsirigos, A., Howell, A. and Martinez-Outschoorn, U.E. (2010) Glycolytic cancer associated fibroblasts promote breast cancer tumor growth, without a measurable increase in angiogenesis: Evidence for stromal-epithelial metabolic coupling. Cell Cycle, 9(12): 2412-2422.

83. Li, K.K.W., Pang, J.C.S., Ching, A.K.K., Wong, C.K., Kong, X., Wang, Y., Zhou, L., Chen, Z. and Ng, H.K. (2009) miR-124 is frequently down-regulated in medulloblastoma and is a negative regulator of SLC16A1. Hum. Pathol., 40(9): 1234-1243.

84. Tripathi, A.K., Koringa, P.G., Jakhesara, S.J., Ahir, V.B., Ramani, U.V., Bhatt, V.D., Sajnani, M.R., Patel, D.A., Joshi, A.J., Shanmuga, S.J. and Rank, D.N. (2012) A preliminary sketch of horn cancer transcriptome in Indian zebu cattle. Gene, 493(1): 124-131.

85. Uhlen, M., Oksvold, P., Fagerberg, L., Lundberg, E., Jonasson, K., Forsberg, M., Zwahlen, M., Kampf, C., Wester, K., Hober, S. and Wernerus, H. (2010) Towards a knowledge-based human protein atlas. Nat. Biotechnol., 28(12): 1248-1250.

86. Das, S., Samant, R.S. and Shevde, L.A. (2011) Hedgehog signaling induced by breast cancer cells promotes osteoclastogenesis and osteolysis. J. Biol. Chem., 286(11): 9612-9622.

87. Ferraro, A., Schepis, F., Leone, V., Federico, A., Borbone, E., Pallante, P., Berlingieri, M.T., Chiappetta, G., Monaco, M., Palmieri, D. and Chiariotti, L. (2013) Tumor suppressor role of the CL2/DRO1/CCDC80 gene in thyroid carcinogenesis. J. Clin. Endocrinol. Metab., 98(7): 2834-2843.

88. Hjerpe, E., Brage, S.E., Carlson, J., Stolt, M.F., Schedvins, K., Johansson, H., Shoshan, M. and Lundqvist, E.A. (2013) Metabolic markers GAPDH, PKM2, ATP5B and BECindex in advanced serous ovarian cancer. BMC Clin. Pathol., 13(1): 1.

89. Li, X., Roslan, S., Johnstone, C.N., Wright, J.A., Bracken, C.P., Anderson, M., Bert, A.G., Selth, L.A., Anderson, R.L., Goodall, G.J. and Gregory, P.A. (2014) MiR-200 can repress breast cancer metastasis through ZEB1-independent but moesin-dependent pathways. Oncogene, 33(31): 4077-4088.

90. Singhi, A.D., Mathews, A.C., Jenkins, R.B., Lan, F., Fink, S.R., Nassar, H., Vang, R., Fetting, J.H., Hicks, J., Sukumar, S. and De Marzo, A.M. (2012) MYC gene amplification is often acquired in lethal distant breast cancer metastases of unamplified primary tumors. Modern Pathol., 25(3): 378-387.

91. Rokavec, M., Öner, M.G., Li, H., Jackstadt, R., Jiang, L., Lodygin, D., Kaller, M., Horst, D., Ziegler, P.K., Schwitalla, S. and Slotta-Huspenina, J. (2014) IL-6R/ STAT3/miR-34a feedback loop promotes EMT-mediated colorectal cancer invasion and metastasis. J. Clin. Invest., 124(4): 1853-1867.

92. Tell, R.W. and Horvath, C.M. (2014) Bioinformatic analysis reveals a pattern of STAT3-associated gene expression specific to basal-like breast cancers in human tumors. Proc. Natl. Acad. Sci., 111(35): 12787-12792.

93. Kumar, V.P., Sehgal, P., Thota, B., Patil, S., Santosh, V. and Kondaiah, P. (2014) Insulin like growth factor binding protein 4 promotes GBM progression and regulates key factors involved in EMT and invasion. J. Neuro Oncol., 116(3): 455-464.

94. Ueno, K., Hirata, H., Majid, S., Tabatabai, Z.L., Hinoda, Y. and Dahiya, R. (2011) IGFBP-4 activates the Wnt/beta-catenin signaling pathway and induces M-CAM expression in human renal cell carcinoma. Int. J. Cancer, 129(10):
2360-2369.

95. Wen, D., Geng, J., Li, W., Guo, C. and Zheng, J. (2014) A computational bioinformatics analysis of gene expression identifies candidate agents for prostate cancer. Andrologia, 46(6): 625-632.

96. Sorrells, S., Carbonneau, S., Harrington, E., Chen, A.T., Hast, B., Milash, B., Pyati, U., Major, M.B., Zhou, Y., Zon, L.I. and Stewart, R.A. (2012) Ccdc94 protects cells from ionizing radiation by inhibiting the expression of $\mathrm{p} 53$. PLoS Genet., 8(8): e1002922.

97. Goicoechea, S.M., Bednarski, B., Garcia-Mata, R., PrenticeDunn, H., Kim, H.J. and Otey, C.A. (2009) Palladin contributes to invasive motility in human breast cancer cells. Oncogene, 28(4): 587-598.

98. Bhattacharya, R., Kwon, J., Ali, B., Wang, E., Patra, S., Shridhar, V. and Mukherjee, P. (2008) Role of hedgehog signaling in ovarian cancer. Clin. Cancer Res., 14(23): 7659-7666.

99. Mourtada, J.S., Yang, D., Tworowska, I., Larson, R., Smith, D., Tsao, N., Opdenaker, L., Mourtada, F. and Woodward, W. (2012) Detection of canonical hedgehog signaling in breast cancer by 131-iodine-labeled derivatives of the sonic hedgehog protein. BioMed Res. Int., 11: 257-258.

100. Kang, H.C., Wakabayashi, Y., Jen, K.Y., Mao, J.H., Zoumpourlis, V., Del Rosario, R. and Balmain, A. (2013) Ptch1 overexpression drives skin carcinogenesis and developmental defects in K14Ptch FVB mice. J. Invest. Dermatol., 133(5): 1311-1320.

101. Zhang, J., Zheng, F., Yu, G., Yin, Y. and Lu, Q. (2013) miR196a targets netrin 4 and regulates cell proliferation and migration of cervical cancer cells. Biochem. Biophys. Res. Commun., 440(4): 582-588

102. Wan, F., Cheng, C., Wang, Z., Xiao, X., Zeng, H., Xing, S., Chen, X., Wang, J., Li, S., Zhang, Y. and Xiang, W. (2015) SATB1 overexpression regulates the development and progression in bladder cancer through EMT. PLoS One, 10(2): $\mathrm{e} 0117518$.

103. Wang, Z., Hou, J., Lu, L., Qi, Z., Sun, J., Gao, W., Meng, J., Wang, Y., Sun, H., Gu, H. and Xin, Y. (2013) Small ribosomal protein subunit $\mathrm{S} 7$ suppresses ovarian tumorigenesis through regulation of the PI3K/AKT and MAPK pathways. PLoS One, 8(11): e79117.

104. Yu, C., Luo, C., Qu, B., Khudhair, N., Gu, X., Zang, Y., Wang, C., Zhang, N., Li, Q. and Gao, X. (2014) Molecular network including eIF1AX, RPS7, and 14-3-3 $\gamma$ regulates protein translation and cell proliferation in bovine mammary epithelial cells. Arch. Biochem. Biophys., 564: 142-155.

105. Bachelor, M.A., Lu, Y. and Owens, D.M. (2011) L-3Phosphoserine phosphatase (PSPH) regulates cutaneous squamous cell carcinoma proliferation independent of L-serine biosynthesis. J. Dermatol. Sci., 63(3): 164-172.

106. Cheng, Y., Liu, W., Kim, S.T., Sun, J., Lu, L., Sun, J., Zheng, S.L., Isaacs, W.B. and Xu, J. (2011) Evaluation of PPP2R2A as a prostate cancer susceptibility gene: A comprehensive germline and somatic study. Cancer Genet., 204(7): 375-381

107. Liu, X., Liu, Q., Fan, Y., Wang, S., Liu, X., Zhu, L., Liu, M. and Tang, H. (2014) Downregulation of PPP2R5E expression by miR-23a suppresses apoptosis to facilitate the growth of gastric cancer cells. FEBS Lett., 588(17): 3160-3169.

108. Erickson, J.W. and Cerione, R.A. (2010) Glutaminase: A hot spot for regulation of cancer cell metabolism? Oncotarget, 1(8): 734-740.

109. Nilsson, J.A. and Cleveland, J.L. (2003) Myc pathways provoking cell suicide and cancer. Oncogene, 22(56): 9007-9021.

110. Lu, Y., Yi, Y., Liu, P., Wen, W., James, M., Wang, D. and You, M. (2007) Common human cancer genes discovered by integrated gene-expression analysis. PLoS One, 2(11): e1149.

111. Woeller, C.F., Anderson, D.D., Szebenyi, D.M. and 
Stover, P.J. (2007) Evidence for small ubiquitin-like modifier-dependent nuclear import of the thymidylate biosynthesis pathway. J. Biol. Chem., 282(24): 17623-17631.

112. Anderson, D.D., Woeller, C.F. and Stover, P.J. (2007) Small ubiquitin-like modifier-1 (SUMO-1) modification of thymidylate synthase and dihydrofolate reductase. Clin. Chem. Lab. Med., 45(12): 1760-1763.

113. Fernández-Chacón, R. and Südhof, T.C. (2000) Novel SCAMPs lacking NPF repeats: Ubiquitous and synaptic vesicle-specific forms implicate SCAMPs in multiple membrane-trafficking functions. $J$. Neurosci., 20(21): 7941-7950.

114. Vogelstein, B. and Kinzler, K.W. (2004) Cancer genes and the pathways they control. Nat. Med., 10(8): 789-799.

115. Dawany, N.B., Dampier, W.N. and Tozeren, A. (2011) Large-scale integration of microarray data reveals genes and pathways common to multiple cancer types. Int. J. Cancer, 128(12): 2881-2891.

$* * * * * * * *$ 